\title{
A comparison of OEM CO retrievals from the IASI and MOPITT instruments
}

\author{
S. M. Illingworth ${ }^{1}$, J. J. Remedios ${ }^{1}$, H. Boesch ${ }^{1}$, S.-P. Ho ${ }^{2}$, D. P. Edwards ${ }^{2}$, P. I. Palmer ${ }^{3}$, and S. Gonzi ${ }^{3}$ \\ ${ }^{1}$ Earth Observation Science, Department of Physics and Astronomy, University of Leicester, Leicester, UK \\ ${ }^{2}$ Atmospheric Chemistry Division, National Center for Atmospheric Research, Boulder, Colorado, USA \\ ${ }^{3}$ School of GeoSciences, University of Edinburgh, Edinburgh, UK
}

Received: 20 September 2010 - Published in Atmos. Meas. Tech. Discuss.: 10 November 2010

Revised: 2 April 2011 - Accepted: 21 April 2011 - Published: 2 May 2011

\begin{abstract}
Observations of atmospheric carbon monoxide (CO) can only be made on continental and global scales by remote sensing instruments situated in space. One such instrument is the Infrared Atmospheric Sounding Interferometer (IASI), producing spectrally resolved, top-of-atmosphere radiance measurements from which $\mathrm{CO}$ vertical layers and total columns can be retrieved. This paper presents a technique for intercomparisons of satellite data with low vertical resolution. The example in the paper also generates the first intercomparison between an IASI CO data set, in this case that produced by the University of Leicester IASI Retrieval Scheme (ULIRS), and the V3 and V4 operationally retrieved $\mathrm{CO}$ products from the Measurements Of Pollution In The Troposphere (MOPITT) instrument. The comparison is performed for a localised region of Africa, primarily for an ocean day-time configuration, in order to develop the technique for instrument intercomparison in a region with well defined a priori.

By comparing both the standard data and a special version of MOPITT data retrieved using the ULIRS a priori for $\mathrm{CO}$, it is shown that standard intercomparisons of $\mathrm{CO}$ are strongly affected by the differing a priori data of the retrievals, and by the differing sensitivities of the two instruments. In particular, the differing a priori profiles for MOPITT V3 and V4 data result in systematic retrieved profile changes as expected. An application of averaging kernels is used to derive a difference quantity which is much less affected by smoothing error, and hence more sensitive to systematic error. These conclusions are confirmed by simulations with model profiles for the same region. This technique is used to show
\end{abstract}

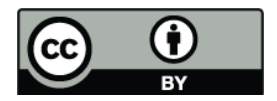

Correspondence to: S. Illingworth (smi3@le.ac.uk) that for the data that has been processed the systematic bias between MOPITT V4 and ULIRS IASI data, at MOPITT vertical resolution, is less than $7 \%$ for the comparison data set, and on average appears to be less than $4 \%$. The results of this study indicate that intercomparisons of satellite data sets with low vertical resolution should ideally be performed with: retrievals using a common a priori appropriate to the geographic region studied; the application of averaging kernels to compute difference quantities with reduced a priori influence; and a comparison with simulated differences using model profiles for the target gas in the region.

\section{Introduction}

Carbon monoxide $(\mathrm{CO})$ in the troposphere acts as a marker, or tracer, of incomplete combustion processes, and through its reactions with the hydroxyl free radical $\mathrm{OH}$, the concentration of $\mathrm{CO}$ is related to the oxidising capacity of the troposphere (Thompson, 1992); investigations into perturbations of the sources, sinks and net surface fluxes of $\mathrm{CO}$ are therefore of significant importance.

Whilst ground-based and aircraft-mounted instruments are able to make precise measurements of the tropospheric concentrations of $\mathrm{CO}$, they are not able to provide large-scale regional or global coverage. Only observations from space allow such measurements (in the absence of cloud) to be made over a reasonably short time period. Over the past decade the MOPITT (Measurements of Pollution in the Troposphere Deeter et al., 2003), IMG (Interferometer Monitor for greenhouse Gases) (Kobayashi et al., 1999), AIRS (Atmospheric InfraRed Sounder) (McMillan et al., 2005), and TES (Tropospheric Emission Spectrometer) (Rinsland et al.,

Published by Copernicus Publications on behalf of the European Geosciences Union. 
2006) instruments have all successfully exploited observations in the $4.7 \mu \mathrm{m}$ spectral band to increase the vertical information content of profiles and also global coverage. The IASI (Infrared Atmospheric Sounding Interferometer) is the latest instrument in the Thermal InfraRed (TIR) suite of tropospheric sounders, and the University of Leicester IASI Retrieval Scheme (ULIRS) has been developed to convert IASI Top Of Atmosphere (TOA) radiances into an atmospheric CO product (Illingworth et al., 2011).

The objectives of this paper are to examine the consistency between the MOPITT and ULIRS retrieved IASI data (hereafter referred to simply as the IASI data or product), to use this assessment of TIR tropospheric CO data to develop a technique for intercomparing satellite data with low vertical resolution, and to investigate some of the probable effects which give rise to the differences that are observed. This work follows on from other studies which have investigated the intercomparison of $\mathrm{CO}$ from different satellite products, such as Luo et al. (2007); Ho et al. (2009); George et al. (2009); Warner et al. (2007); Kopacz et al. (2010), and this paper is organised as follows. In Sect. 2 we summarise the characteristics of the IASI instrument, and discuss the setup of the ULIRS. Section 3 introduces the MOPITT instrument and presents in detail the retrieval algorithm of the MOPITT CO product, in particular highlighting the similarities and differences between the V3 and V4 operational products. Section 4 presents the results of a standard intercomparison between the IASI and MOPITT instruments and their retrieved CO products, with Sect. 5 performing the analysis with a consistent set of a priori statistics. This section also compares the observed differences between instruments with systematic differences computed using modelled profiles. Finally in Sect. 6 we apply the methodology of Rodgers and Connor (2003) to undertake a comparison with reduced smoothing error, as demonstrated using synthetic $\mathrm{CO}$ fields as for Sect. 5. The conclusions of this work are summarised in Sect. 7.

\section{IASI CO retrievals}

\subsection{IASI}

The IASI instrument is a high-resolution Michelson interferometer which was launched in 2007, onboard EUMETSAT's (European Organisation for the Exploitation of Meteorological Satellites) MetOp-A satellite, with an equator crossing time of 09:30 LST (Local Solar Time) and an instantaneous Field of View (IFOV) that is approximately $12 \mathrm{~km}$ in diameter at nadir; it covers the spectral range between 645 and $2760 \mathrm{~cm}^{-1}$, with a spectral sampling of $0.25 \mathrm{~cm}^{-1}$ and a nominal apodised spectral resolution of $0.5 \mathrm{~cm}^{-1}$ (Blumstein et al., 2004). A more detailed description of the IASI instrument is given in Clerbaux et al. (2009); here we briefly discuss why the IASI is well suited for providing detailed information about the global distribution of $\mathrm{CO}$, on both short and long term timescales.

The IASI instrument's spectral range and low noise in the $4.7 \mu \mathrm{m}$ region, mean that it is able to observe the $\mathrm{CO}$ spectral band centred on $2140 \mathrm{~cm}^{1}(4.7 \mu \mathrm{m})$; the large swath width $(2200 \mathrm{~km})$ enables IASI to achieve a twice daily global coverage ( $\sim 99 \%)$, and as the first of a series of three instruments to be launched every five years, the IASI will allow for the monitoring of long-term climatological trends at a very high temporal resolution.

Illingworth et al. (2009) have demonstrated that the likely accuracy in band 1 of the IASI instrument is $<0.1 \mathrm{~K}$ at $11 \mu \mathrm{m}$. By considering work done by Larar et al. (2010), and also the internal radiometric accuracy of the IASI instrument, as reported by Blumstein et al. (2004), the IASI instrument is likely radiometrically accurate to $<0.3 \mathrm{~K}$ in the $4.7 \mu \mathrm{m}$ spectral region.

\subsection{The ULIRS retrieval setup}

The ULIRS scheme (Illingworth et al., 2011) has been developed to retrieve $\mathrm{CO}$ from IASI measured TOA radiances, utilising an Optimal Estimation Method (OEM) (Rodgers, 2000) to constrain the ill-conditioned nature of the retrieval problem. A summary of the main features of the ULIRS are now presented, with a full description given in (Illingworth et al., 2011). The ULIRS makes use of the spectral interval 2143 to $2181 \mathrm{~cm}^{-1}$, for reasons outlined in Barret et al. (2005), in which CO and water vapour are the primary absorbers/emitters. The retrieval state vector comprises profiles of $\mathrm{CO}$, temperature and $\mathrm{H}_{2} \mathrm{O}$ based on a 30 level grid equidistant in pressure between surface pressure and $50 \mathrm{hPa}$. Surface temperature is also retrieved. Convergence of the retrieval equations is achieved using a Levenberg-Marquardt iterative technique with both cost function changes and maximum numbers of iterations specified. The ULIRS also utilises a spatially precise (30" surface elevation USGS, 1998) and emissivity $\left(0.05^{\circ}\right.$ resolution, Seemann et al., 2008). The importance of these three parameters, as well as full details of the ULIRS are discussed in Illingworth et al. (2011).

In order to maintain accuracy, the ULIRS employs the Reference Forward Model (RFM) as a forward model. The RFM is an accurate line-by-line Radiative Transfer (RT) model, which was developed at the University of Oxford (UK), and can be used to simulate the TOA signal as measured by a space-borne sensor (Dudhia, 2000); the model is based on the GENLN2 RT model (Edwards, 1992). The signals calculated on a fine mesh grid are convolved with the IASI line shape function. The RT calculations also include an estimate of the solar reflected signal from the Earth's surface as described in Illingworth et al. (2011). The RFM computes a jacobian product as part of its output. It does this by calculating the result of a $1 \%$ perturbation to the profile level for trace gases and a $1 \mathrm{~K}$ perturbation for atmospheric temperature. 
Details of construction of the a priori are extensively described in Illingworth et al. (2011). The important aspect for this paper is that a single averaged $\mathrm{CO}$ a priori profile and covariance were constructed specifically for the region of Africa bounded longitudinally from -20 to $50^{\circ} \mathrm{E}$, and latitudinally from -30 to $30^{\circ} \mathrm{N}$. The data utilised were outputs from the Toulouse Off-line Model of Chemistry And Transport (TOMCAT) Chemical Transport Model (CTM) Chipperfield (2006), run over an entire year with a selection of profiles for which the surface a priori was greater than $100 \mathrm{ppbv}$. Hence the a priori data are representative of the region selected for the intercomparisons with a significant bias towards higher $\mathrm{CO}$ columns more representative of a regional average for regions with biomass burning (such as the day under study). The use of a single a priori profile for all retrievals is in common with the approach taken for some MOPITT data sets (see Sect. 3.2). The a priori data for $\mathrm{CO}$ are plotted in Fig. 1. The a priori tropospheric temperature and water vapour profiles used in the ULIRS algorithm are taken from the European Centre for Medium-Range Weather Forecasts (ECMWF) operational data set, courtesy of the British Atmospheric Data Centre (BADC). This data set is on a $1.125^{\circ} \times 1.125^{\circ}$ grid with 91 pressure levels, and a 6 hourly time resolution.

A thorough characterisation of the retrievals for the selected region of Africa shows that it the high quality TOA radiances measured by the IASI instrument enable the retrieval of between 1 and 2 pieces of information about the tropospheric CO vertical profiles for the data in this paper. The full error analysis of Illingworth et al. (2011) showed that the main source of error is the smoothing error, with an added contribution from the measurement error in the lower-middle troposphere. Typical errors for the African region relating to the profiles are found to be approx. $20 \%$ at 5 and $12 \mathrm{~km}$, and on the total columns to be approximately $24 \%$. These errors include a smoothing term; neglecting the smoothing error the total random errors are found to be approx. $10 \%$ at 5 and $12 \mathrm{~km}$, and on the total columns to be approximately $12 \%$. Simulated retrievals for a wide range of profiles show column biases of less than $3 \%$.

As well as the retrievals from the ULIRS, CO products have also been retrieved from the IASI radiance spectra in a near real time mode (observation $+3 \mathrm{~h}$ ) at LATMOS (Laboratoire Atmospheres, Milieux, Observations Spatiales), using the FORLI-CO (Turquety et al., 2009), a retrieval code based on optimal estimation. These retrieved profiles are defined on a vertical grid of 19 standard levels (from 0.5 to $18.5 \mathrm{~km}$ ) on a global scale, although less reliable retrievals have been reported for latitudes within $25^{\circ}$ from the poles, at nighttime, and at locations with surface emissivity greater than 0.98 or lower than 0.93. Global comparisons for the FORLI-CO data set with other sensors, but in a more limited theoretical manner, have been reported by George et al. (2009). The ULIRS retrieval scheme differs from the FORLI-CO scheme in having a vertical grid floating in pressure, in having explicit

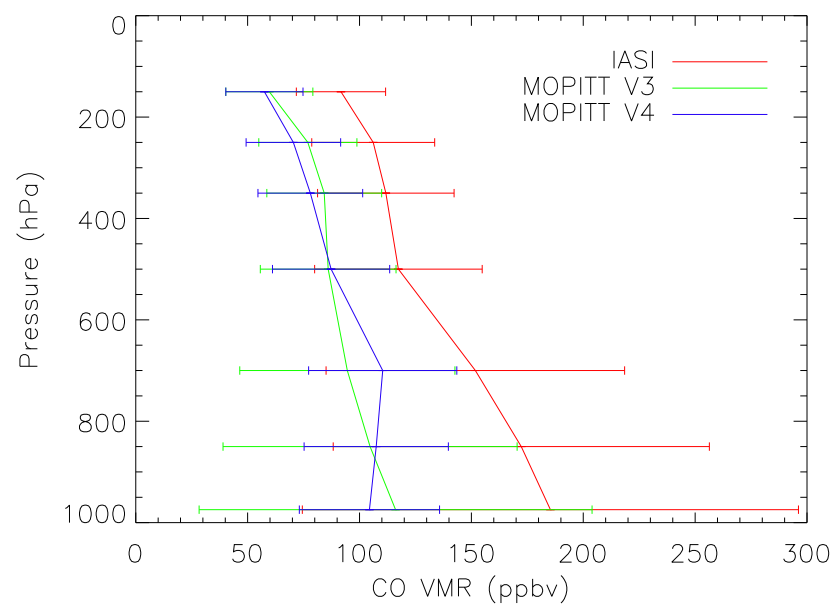

Fig. 1. IASI and MOPITT V3 a priori profile and associated errors (i.e. the diagonal of the a priori covariance matrix), as well as the MOPITT V4 a priori profile averaged over the region shown in Fig. 4 for 1 September 2007. The profiles have all been interpolated onto the MOPITT V3 pressure grid for ease of reference.

emissivity and topography, and by including a detailed solar spectrum in the forward model. For the purposes of this paper, it should be noted that an important consideration is that the ULIRS IASI retrieval has been performed with a specific a priori appropriate to the geographical region of the comparison ensemble, a significant fact as explained in later sections.

\section{MOPITT CO retrievals}

\subsection{MOPITT}

A summary of the main characteristics of the MOPITT instrument is given below; for a full description of the instrument (see e.g. Drummond and Mand, 1996). MOPITT is a nadir sounding instrument which measures upwelling infrared radiation in both the $4.7 \mu \mathrm{m}$ and 2.4 mum spectral bands; it uses gas correlation spectroscopy using Pressure Modulation Cells (PMC) and Length Modulation Cells (LMCs) to calculate total column amounts and profiles of $\mathrm{CO}$ in the lower atmosphere. MOPITT was launched on board the Terra satellite in 1999, with an equator crossing time of $10: 30 \mathrm{LST} \pm 26 \mathrm{~min}$, and a total scanning angle of $\pm 26^{\circ}$ in each swath, combined with a 22 by $22 \mathrm{~km}$ horizontal resolution allows MOPITT to generate a global map of $\mathrm{CO}$ once every three days. For the purposes of this work we are interested in the measurements made in the $4.7 \mu \mathrm{m}$ region, which provide the most information in regards to a retrieved profile of CO. Whilst MOPITT utilises a slightly different technique to IASI in its measurements of TOA radiances, the sensitivity of the two instruments are determined by the same factors. 


\subsection{Retrieval setup}

The MOPITT "version 3" (V3) product first became available in 2002, and was the first data set to offer truly long-term and global coverage about the distribution of tropospheric $\mathrm{CO}$. The characteristics of this product are given in detail by Deeter et al. (2003), but to summarise they include: (1) an OEM retrieval algorithm, which utilises an operational radiative transfer model (MOPFAS) (Edwards et al., 1999) based on prelaunch laboratory measurements of instrument parameters as its forward model; (2) a fixed 7-level pressure grid (floating surface level, $850 \mathrm{hPa}, 700 \mathrm{hPa}, 500 \mathrm{hPa}, 350 \mathrm{hPa}$, $250 \mathrm{hPa}, 150 \mathrm{hPa}$ ); (3) a global a priori profile and covariance matrix for all retrievals; and (4) a state vector which consists of a CO profile, given in terms of a Volume Mixing Ratio (VMR), a surface temperature and a surface emissivity.

A full description of the MOPITT "version 4" (V4) product is given by Deeter et al. (2010). As with the V3 product, the V4 algorithm is based on an OEM retrieval technique, using MOPFAS as the forward model. There are however significant differences between the V3 and V4 algorithms, and some of these are now discussed. Whereas the V3 state vector represented the $\mathrm{CO}$ vertical profile as a set of VMR values, the V4 state vector represents the $\mathrm{CO}$ profile as a set of $\log (\mathrm{VMR})$ values; it was found that the use of a VMR probability distribution function in $\mathrm{V} 3$ occasionally resulted in unrealistic negative VMR values, and so by representing the $\mathrm{CO}$ profile and covariance in $\log (\mathrm{VMR})$ space in the $\mathrm{V} 4$ product, these negative values were eliminated. In addition to this, the V4 state vector expresses the $\mathrm{CO}$ profile on a 10level pressure grid (floating surface level followed by nine uniformly spaced levels from 900 to $100 \mathrm{hPa}$ ) instead of the seven-level grid used for V3; this change to an equidistant pressure grid was implemented because a retrieval grid with uniform grid spacing simplifies the physical interpretation of the retrieval.

For the V4 product some changes to the MOPFAS radiative transfer model were also made in comparison to that used in the V3 algorithm. In extremely polluted conditions, V3 retrievals sometimes failed because they exceeded the upper CO concentration limit of MOPFAS. For the V4 product the MOPFAS forward model was therefore modified to allow for retrievals with significantly higher values, with the number of training profiles expanded from 58 (Edwards et al., 1999) to 116. As part of its processing, MOPFAS also incorporates models of the physical states of the MOPITT LMCs and PMCs, and for the V4 algorithm, both the PMC and LMC models have been updated for consistency with the actual on-orbit cell pressure and temperature values observed during the mission. Specifically, the pressure and temperature values that are used to model the LMCs in MOPFAS are now time-mean values, whilst the shapes and relative phases of the PMC pressure and temperature cycles remain unchanged. These updated models also reflect instrumental modifications performed after the failure of one of MOPITT's two coolers which occurred on 7 May 2001.

One of the most significant differences between the MOPITT V3 and V4 retrieval algorithms is the choice of the a priori profiles and covariance matrices. In the MOPITT V3 product, a global a priori profile was employed for all retrievals; the use of a single profile allows for an easier interpretation of retrieved data in terms of smoothing and bias influences from the a priori. However, it is also true that using a global a priori can sometimes yield large systematic differences between the "true" $\mathrm{CO}$ concentration and the retrieved value, at levels where the weighting functions exhibit low sensitivity; this is especially true for the large smoothing length $(500 \mathrm{hPa}$, calculated by computing the delta-pressure for which the off-diagonal element of the covariance matrix was found to be $1 / e^{2}$ times the corresponding diagonal element) of the MOPITT V3 a priori covariance matrix. To reduce these a priori-related errors, V4 a priori profiles are based on a monthly climatology from the global CTM MOZART-4 (Model for OZone And Related chemical Tracers, version 4) (Emmons et al., 2010), where for each retrieval, the climatology is spatially and temporally interpolated to the time and location of the observation. The use of a covariance of $\mathrm{CO}$ profiles in $\log (\mathrm{VMR})$ space describes the relative or fractional VMR variability. This means that whilst utilising a variable a priori profile, a constant and global background covariance matrix of $\log (\mathrm{VMR})$ can be used. As in V3, the V4 algorithm uses a global a priori covariance matrix, but sets the diagonal elements to a fractional VMR variability of $30 \%$, and assumes a smoothing length of $100 \mathrm{hPa}$ (Deeter et al., 2010); these values have been chosen based on analyses of aircraft in situ data sets at individual MOPITT validation sites. This relatively small value for the smoothing length acts to reduce the projection of information from levels where the MOPITT weighting functions are relatively strong (e.g., the mid-lower troposphere) to levels where the weighting functions are relatively weak (e.g., the surface). An example of the differences between the V3 and $\mathrm{V} 4$ a priori profiles and covariances matrices is plotted in Fig. 1.

\subsection{Comparison of MOPITT V3 and V4 averaging kernels}

The averaging kernel matrix $\mathbf{A}$ is a representative of the sensitivity of the retrieved state to the true state:

$\mathbf{A}=\frac{\partial \hat{\boldsymbol{x}}}{\partial \boldsymbol{x}}$.

where $\boldsymbol{x}$ is the "true" state vector, and $\hat{\boldsymbol{x}}$ is the retrieved state vector. The rows of $\mathbf{A}$ are generally peaked functions, which have a half-width that is representative of the spatial resolution of the observing system. An ideal observing system would have $\delta$-function averaging kernels, peaking at the various levels over which the retrieval was performed, and no 

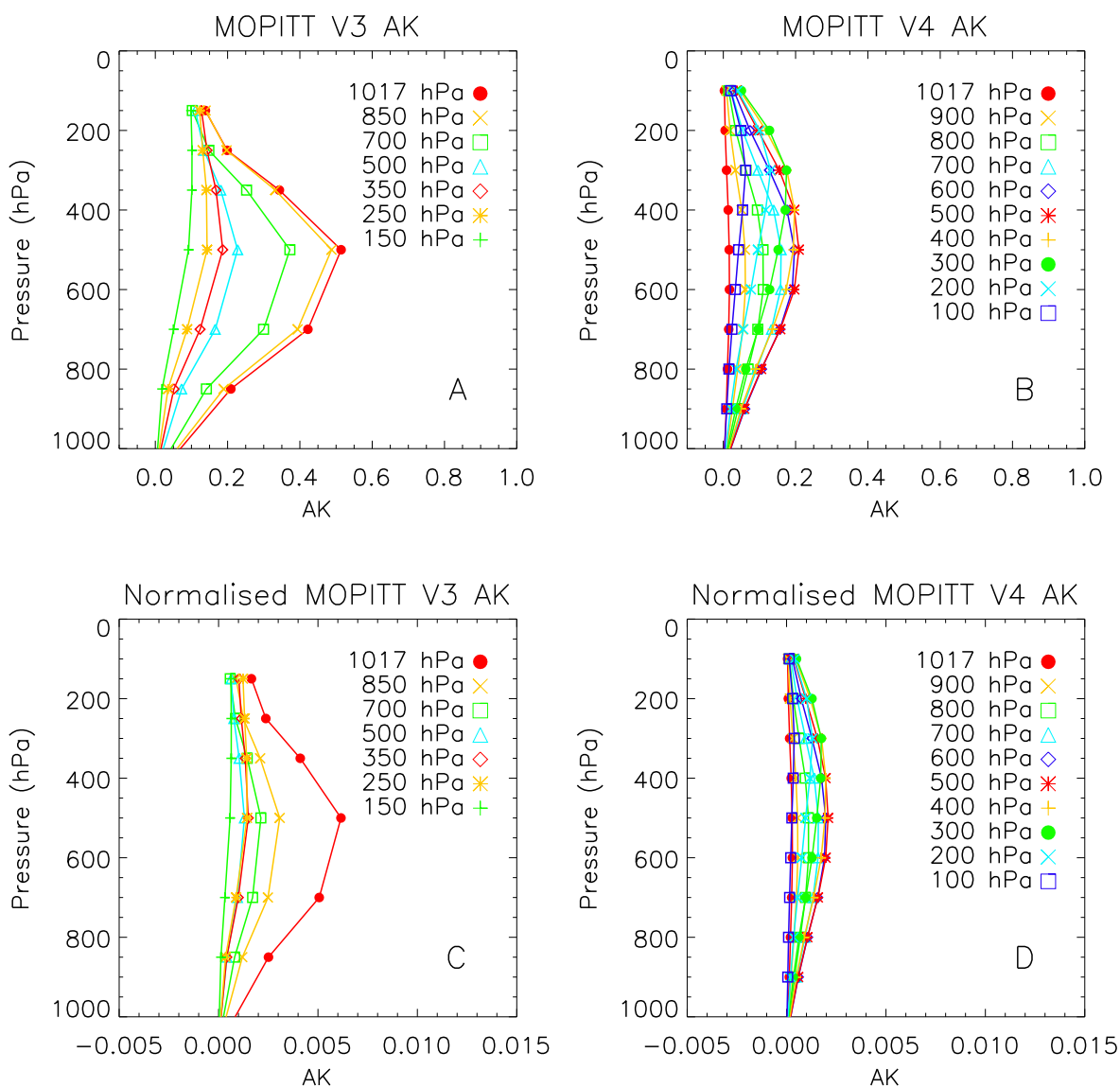

Fig. 2. Averaged daytime and ocean averaging kernels for 1 September 2007 over Southern Africa, for: (A) MOPITT V3 (A ${ }^{\text {OP3 }}$ ), (B) MOPITT V4 ( $\left.\mathbf{A}^{\mathrm{MOP} 4}\right)$, (C) pressure-layer-normalised averaging kernels for MOPITT V3 $\left(\mathbf{A}_{N}^{\mathrm{MOP} 3}\right)$, and (D) pressure-layer-normalised averaging kernels for MOPITT V4 $\left(\mathbf{A}_{N}^{\mathrm{MOP} 4}\right)$.The MOPITT V3 averaging kernels are in normal space, whereas the MOPITT V4 averaging kernels relate to $\log (\mathrm{VMR})$ values, and the units of the pressure-layer-normalised averaging kernels are $\mathrm{hPa}^{-1}$.

noise. The Degrees of Freedom for Signal (DFS) are a measurement of the information content of the retrieval, and are defined as the trace of $\mathbf{A}$ (Rodgers, 2000).

Figure 2 shows a plot of the averaged daytime and oceanic MOPITT V3 and V4 averaging kernels ( $\mathbf{A}^{\mathrm{MOP} 3}$ and $\left.\mathbf{A}^{\mathrm{MOP} 4}\right)$ for 1 September 2007 over the region shown in Fig. 4 (hereafter referred to as the Southern Africa region), at each of the pressure levels for the relevant retrieval grid, and illustrates how the MOPITT V3 and V4 measurements contribute to the retrieved $\mathrm{CO}$ profiles. It is important to note that whilst Fig. 2 gives a good indication as to the sensitivities of the MOPITT V3 and V4 averaging kernels, $\mathbf{A}^{\mathrm{MOP} 3}$ and $\mathbf{A}^{\mathrm{MOP} 4}$ do not represent the same quantity: $\mathbf{A}^{\mathrm{MOP} 3}$ is $\partial \hat{\boldsymbol{x}} / \partial \boldsymbol{x}$, whereas $\mathbf{A}^{\mathrm{MOP} 4}$ is $\partial \log (\hat{\boldsymbol{x}}) / \partial \log (\boldsymbol{x})$. To the first order the V3 and V4 averaging kernels can be converted using the following relationship:

$\frac{\partial \log (\hat{\boldsymbol{x}})}{\partial \log (\boldsymbol{x})}=\left(\frac{\boldsymbol{x}}{\hat{\boldsymbol{x}}}\right) \frac{\partial \hat{\boldsymbol{x}}}{\partial \boldsymbol{x}}$.
Because of the large variations in the averaging kernel matrices between day and night, and over land and ocean, it is important to consider each of these cases separately. If these different scenarios are not analysed individually then there are too many factors that must be accounted for, including but not limited to: varying thermal contrast; varying $\mathrm{CO}$ distributions; varying a priori; and varying surface pressures, to permit a meaningful analysis. Similarly, significant latitudinal effects which make tropical retrievals quite different than polar retrievals, mean that any conclusions will be more justifiable if a specific latitudinal zone or region, rather than a global data set, is analysed.

The main reason for performing this analysis over Southern Africa was because this is the region over which the ULIRS was characterised (Illingworth et al., 2011). This is especially important because the ULIRS a priori is appropriate for the specific area analysed and this is an aspect which is very useful for allowing intercomparisons between retrievals, and between retrieved data and model data. Over Southern Africa, especially during the fire season (which 


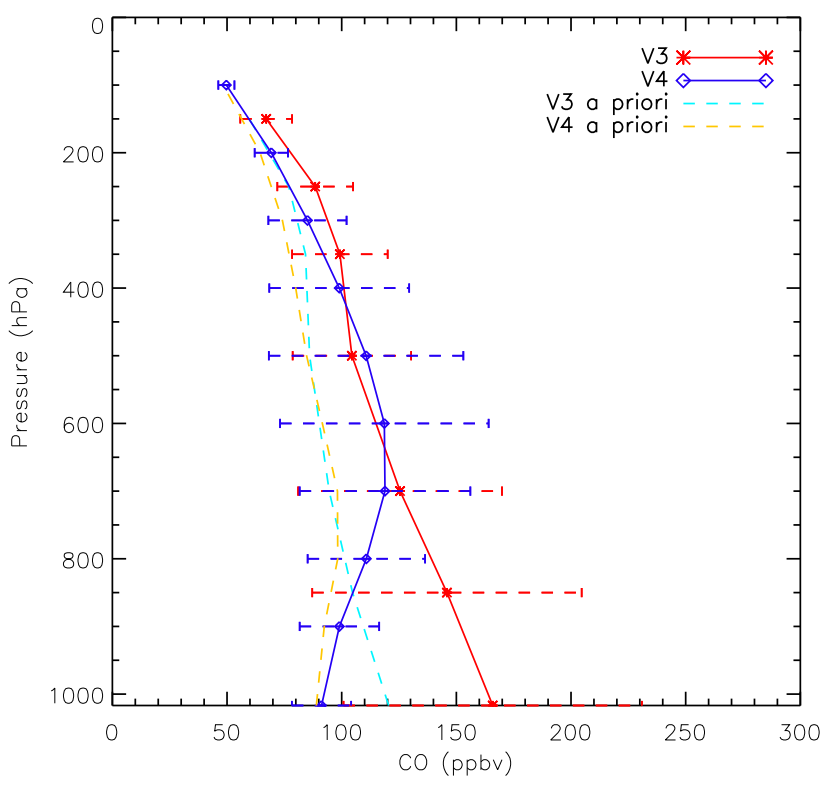

Fig. 3. MOPITT V3 and V4 mean CO profiles (solid red line and blue line, respectively) and standard deviation relative to their means (dashed horizontal lines) for 1 September 2007 over the Southern Africa region, for the daytime and over the ocean. The MOPITT V3 a priori profile (dashed turquoise line), and mean MOPITT V4 a priori profile (dashed yellow line) used in the retrievals are also shown.

typically lasts from late July to early November, Giglio et al., 2006), there is also a large variety in the different $\mathrm{CO}$ atmospheric scenarios; Southern Africa thus represents a region over which a wide variety of $\mathrm{CO}$ profiles can be observed, but which should not be adversely affected by latitudinal effects. It has been shown previously (see e.g. Deeter et al., 2007b) that the thermal contrast has a large effect on the MOPITT averaging kernels, therefore the main comparison has been carried out during daytime over the ocean, where the effects of the thermal contrast are minimised, and where surface emissivity variations can be neglected. From a technique point of view, a consistent use of all the data sets is important.

As the averaging kernels are strongly dependent upon the different pressure grids that are used in each of the retrieval schemes, to make a consistent comparison, the pressurelayer-normalised averaging kernels are generated using the following equation, taken from Ho et al. (2009):

$\mathbf{A}_{N}^{i, j}=\frac{\mathbf{A}^{i, j}}{\Delta P^{i}}$,

where $i$ and $j$ are indexes of column and row elements of $\mathbf{A}$ and $\mathbf{A}_{N}$, and $\Delta P^{i}$ is the pressure thickness of the layer corresponding to column index $i$.

\subsection{Comparison of MOPITT V3 and V4 retrievals}

The mean CO profiles of the MOPITT V3 and MOPITT V4 retrieval algorithms, over the ocean and for the daytime
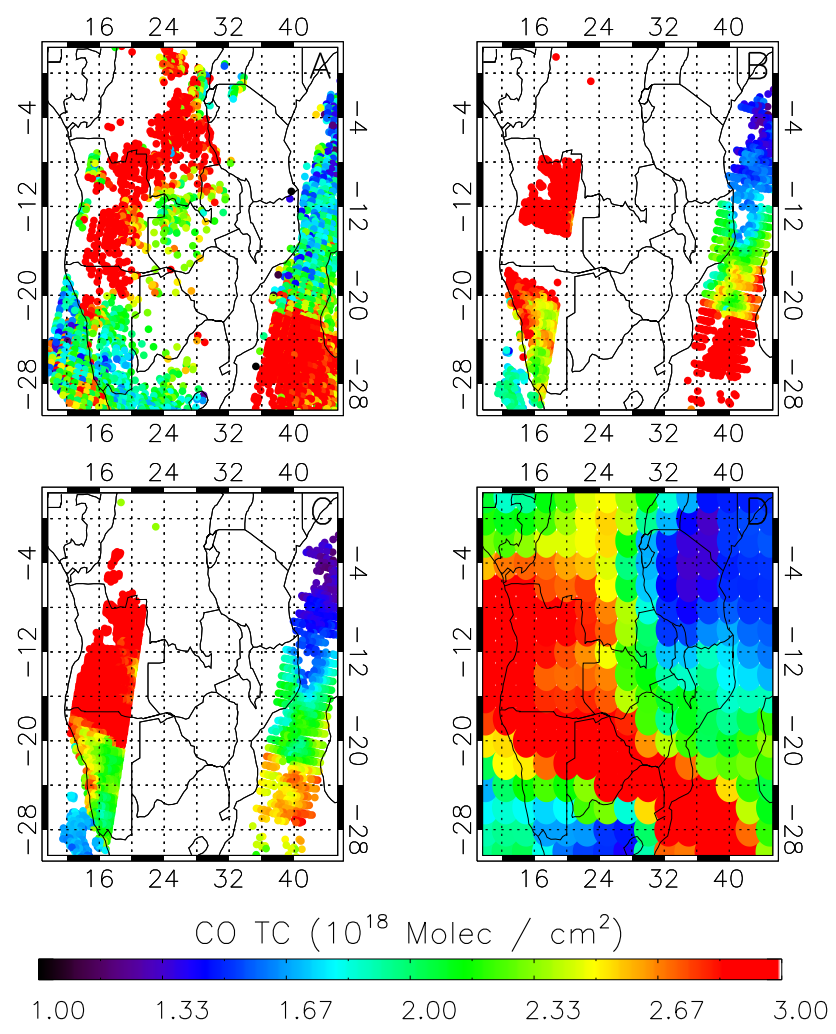

Fig. 4. CO total column density over Southern Africa during the daytime of 1 September 2007: (A) IASI, (B) MOPITT V3, (C) MOPITT V4, and (D) GEOS-Chem.

of 1 September 2007 over the Southern Africa region (see Fig. 4) are shown in Fig. 3. It can be seen that the largest differences between the MOPITT V3 and V4 CO concentrations occur at the surface (approximately $70 \mathrm{ppbv}$ ), whilst the smallest differences occur between 400 and $600 \mathrm{hPa}$.

The differences between the MOPITT V3 and MOPITT V4 retrieved profiles shown in Fig. 3 are consistent with the results of Deeter et al. (2010), with the mean V3 and V4 retrieved profiles similar in the upper troposphere, and differing greatly in the lower troposphere. One of the major reasons for the observed differences between the MOPITT V3 and V4 profiles is the use of different a priori (profiles and covariance matrices), and the effect of the smoothing length on the retrievals. In particular, for large correlation lengths, retrievals at pressure levels that are insensitive to $\mathrm{CO}$ can be strongly influenced by more sensitive levels. One example of where this "false influence" can occur is for scenes with a low-thermal contrast, and hence a lack of sensitivity to the surface; in such scenes a large correlation length can result in the projection of $\mathrm{CO}$ features from the midtroposphere, where there is an increased sensitivity, to the surface. Such a phenomena could well be responsible for the results seen in Fig. 3, with a large difference at the surface suggesting such an effect (see also Sect. 5). 
Table 1. Mean and percentage biases for IASI and MOPITT V3 CO profiles, as well as the mean absolute total column biases between the two products, for daytime over the oceanic Southern Africa region on 1 September 2007. N represents the number of retrievals, and the parentheses denote the standard deviations relative to the mean. Note also that the percentage biases represent the ratio to the mean IASI value.

\begin{tabular}{|c|c|c|c|c|c|}
\hline & $\boldsymbol{x}^{\mathrm{MOP} 3}-\boldsymbol{x}^{\mathrm{IASI}}(N=987)$ & $x^{\mathrm{MOP3}^{\prime}}-x^{\text {IASI }}(N=974)$ & $\delta_{\text {MODEL }}(N=975)$ & $x^{\mathrm{MOP}^{\prime}}-x^{\mathrm{IASI}^{\prime}}(N=972)$ & $\delta_{\text {MODEL }}(N=972)$ \\
\hline \multicolumn{6}{|l|}{$850 \mathrm{hPA}$} \\
\hline Mean (ppv) & $-12.8(61.4)$ & $-14.1(62.9)$ & $-30.3(18.5)$ & $11.2(39.1)$ & $7.3(14.6)$ \\
\hline Bias $(\%)$ & $-7.7(36.9)$ & $-8.5(37.8)$ & $-18.7(11.4)$ & $8.0(27.8)$ & $5.9(11.8)$ \\
\hline \multicolumn{6}{|l|}{$500 \mathrm{hPA}$} \\
\hline Mean (ppv) & $14.5(19.1)$ & $8.1(20.5)$ & $7.0(7.1)$ & $5.7(12.8)$ & $3.6(5.5)$ \\
\hline Bias $(\%)$ & $15.6(20.5)$ & $8.8(22.1)$ & $8.0(8.1)$ & $6.0(13.4)$ & $4.1(6.3)$ \\
\hline \multicolumn{6}{|l|}{$250 \mathrm{hPa}$} \\
\hline Mean (ppv) & $13.9(16.8)$ & $17.9(18.3)$ & $17.2(10.2)$ & $1.5(8.8)$ & $1.5(2.1)$ \\
\hline Bias (\%) & $18.2(22.0)$ & $23.6(24.1)$ & $23.3(13.8)$ & $1.6(9.5)$ & $1.7(2.4)$ \\
\hline \multicolumn{6}{|l|}{ Total column } \\
\hline Absolute Bias (\%) & $1.2(20.3)$ & $2.4(20.4)$ & $1.8(6.1)$ & $6.4(17.5)$ & $4.0(7.3)$ \\
\hline
\end{tabular}

Another possible cause of the differences between the $\mathrm{V} 3 / \mathrm{V} 4$ retrieved profiles is the use of lognormal statistics in the MOPITT V4 retrieval algorithm. Deeter et al. (2007a) showed that the assumption of Gaussian VMR variability in the MOPITT V3 retrieval algorithm is inconsistent with insitu data sets, and leads to positive retrieval bias in especially clean conditions (e.g., VMR values less than $60 \mathrm{ppbv}$ ). As $\mathrm{V} 4$ retrievals use a state vector based on $\log (\mathrm{VMR})$ they are therefore not subject to this effect. A further source of the difference between the MOPITT V3 and V4 data sets is the change in retrieval bias due to drifts in the MOPITT LMCs and PMCs (see Sect. 3.2), which are corrected for in the V4 retrieval algorithm, but not in the V3.

\section{Comparison of IASI and MOPITT CO}

MOPITT is on board the Terra satellite, which is on a different orbit to MetOp, it is therefore not possible to find exact coincidences between IASI and MOPITT measurements. Thus, to ensure a reasonable coincidence criteria and sample size, only IASI and MOPITT retrievals that correspond spatially to within $50 \mathrm{~km}$, and which differ on a temporal timescale by at most $90 \mathrm{~min}$ are considered for this intercomparison; $90 \mathrm{~min}$ was chosen, because it allowed for the maximum amount of data to be collated whilst minimising the effects of transportation. The IASI retrievals were further filtered by using the Root Mean Square (RMS) difference between simulated and observed spectra, as well as the $\chi^{2}$ value of the retrieval. Only retrievals which had an RMS difference of less than $3.5 \mathrm{nW} \mathrm{cm}^{-2} \mathrm{~cm}^{1} \mathrm{sr}^{-1}$ and a $\chi^{2}$ of less than 3.5 were considered for the comparison. Any IASI and MOPITT matches where the surface pressures used in the retrieval process differed by more than $20 \mathrm{hPa}$ were also neglected. In addition to this, only data which was flagged as being cloud free by both the ULIRS (Illingworth et al., 2011), and MOPITT (Warner et al., 2001) cloud filtering algorithms was considered for comparison.

The region considered for comparison, along with the retrieved CO total column densities for each of the algorithms is shown in Fig. 4. As was discussed in Sect. 3.3 it is important to consider the day/night and land/ocean retrievals separately, and the remainder of the figures in this study are for the comparison between daytime retrievals over the ocean.

The IASI and MOPITT retrieval algorithms are set up on pressure grids which differently sample the troposphere, thus the IASI retrievals which were on the pressure levels closest to those of the corresponding MOPITT pressure levels were selected for comparison. The MOPITT V3 ( $\left(\mathbf{A}^{\mathrm{MOP} 3}\right)$ and IASI averaging kernels ( $\left.\mathbf{A}^{\text {IASI }}\right)$ are shown in Fig. 5, whilst the MOPITT V4 ( $\left.\mathbf{A}^{\mathrm{MOP} 4}\right)$ and IASI averaging kernels (A $\mathbf{A}^{\mathrm{IASI}}$ ) are shown in Fig. 6. In both of these figures $\mathbf{A}^{\text {IASI }}$ has been plotted at each of the the IASI retrieval pressure levels, but only the profiles which correspond to those closest to the MOPITT pressure levels are shown. These mean averaging kernels $\left(\mathbf{A}^{\mathrm{MOP} 3}, \mathbf{A}^{\mathrm{MOP} 4}\right.$ and $\mathbf{A}^{\mathrm{IASI}}$ ) correspond to daytime and ocean averages from MOPITT and IASI for 1 September 2007 over the Southern Africa region shown in Fig. 4. As with the differences between $\mathbf{A}^{\mathrm{MOP} 3}$ and $\mathbf{A}^{\mathrm{MOP} 4}$, the different magnitudes between $\mathbf{A}^{\text {MOP }}$ and $\mathbf{A}^{\text {IASI }}$ are mainly due to the different pressure layer thicknesses of the retrieval grids used by MOPITT V3/V4 (7/10 layers) and IASI (30 layers). Recall that, whilst the IASI and MOPITT V3 averaging kernels both represent $\partial \hat{\boldsymbol{x}} / \partial \boldsymbol{x}$, the MOPITT V4 averaging kernels correspond to $\partial \log (\hat{\boldsymbol{x}}) / \partial \log (\boldsymbol{x})$.

The MOPITT V3 and IASI mean CO profiles and standard deviation relative to their means are shown in Fig. 7a, at MOPITT V3 pressure levels for the 1 September 2007, over the Southern Africa region for the daytime over the ocean; this dataset corresponds to approximately 1000 profiles (see Table 1). As can be seen from Fig. 7c, $\boldsymbol{x}^{\text {IASI }}$ overestimates $x^{\mathrm{MOP} 3}$ at pressure levels greater than $500 \mathrm{hPa}$, and 
Table 2. Same as Table 1, but for IASI and MOPITT V4 CO retrievals.

\begin{tabular}{|c|c|c|c|c|c|}
\hline & $\boldsymbol{x}^{\mathrm{MOP} 4}-\boldsymbol{x}^{\mathrm{IASI}}(N=1041)$ & $x^{\mathrm{MOP}^{\prime}}-x^{\mathrm{IASI}}(N=1038)$ & $\delta_{\text {MODEL }}(N=1042)$ & $x^{\mathrm{MOP}^{\prime}}-x^{\mathrm{IASI}^{\prime}}(N=1042)$ & $\delta_{\text {MODEL }}(N=1038)$ \\
\hline \multicolumn{6}{|l|}{$900 \mathrm{hPa}$} \\
\hline Mean (ppv) & $-74.4(72.8)$ & $-28.9(66.7)$ & $-41.9(35.9)$ & $3.1(26.9)$ & $3.5(8.1)$ \\
\hline Bias $(\%)$ & $-42.4(41.5)$ & $-16.5(38.0)$ & $-24.3(20.8)$ & $2.2(18.7)$ & $2.8(6.3)$ \\
\hline \multicolumn{6}{|l|}{$500 \mathrm{hPa}$} \\
\hline Mean (ppv) & $22.2(25.4)$ & $2.0(19.8)$ & $3.2(4.2)$ & $2.1(12.0)$ & $4.2(6.3)$ \\
\hline Bias $(\%)$ & $23.6(27.0)$ & $2.2(21.0)$ & $3.6(4.8)$ & $2.3(12.7)$ & $4.8(7.2)$ \\
\hline \multicolumn{6}{|l|}{$200 \mathrm{hPa}$} \\
\hline Mean (ppv) & $-1.4(18.6)$ & $13.5(18.6)$ & $14.3(11.2)$ & $0.5(5.8)$ & $2.4(3.5)$ \\
\hline Bias $(\%)$ & $-1.9(25.6)$ & $18.5(25.5)$ & $20.2(15.9)$ & $0.5(6.8)$ & $2.9(4.2)$ \\
\hline \multicolumn{6}{|l|}{ Total column } \\
\hline Absolute Bias (\%) & $14.0(22.0)$ & $5.6(20.3)$ & $18.4(9.3)$ & $2.9(14.7)$ & $2.5(3.2)$ \\
\hline
\end{tabular}
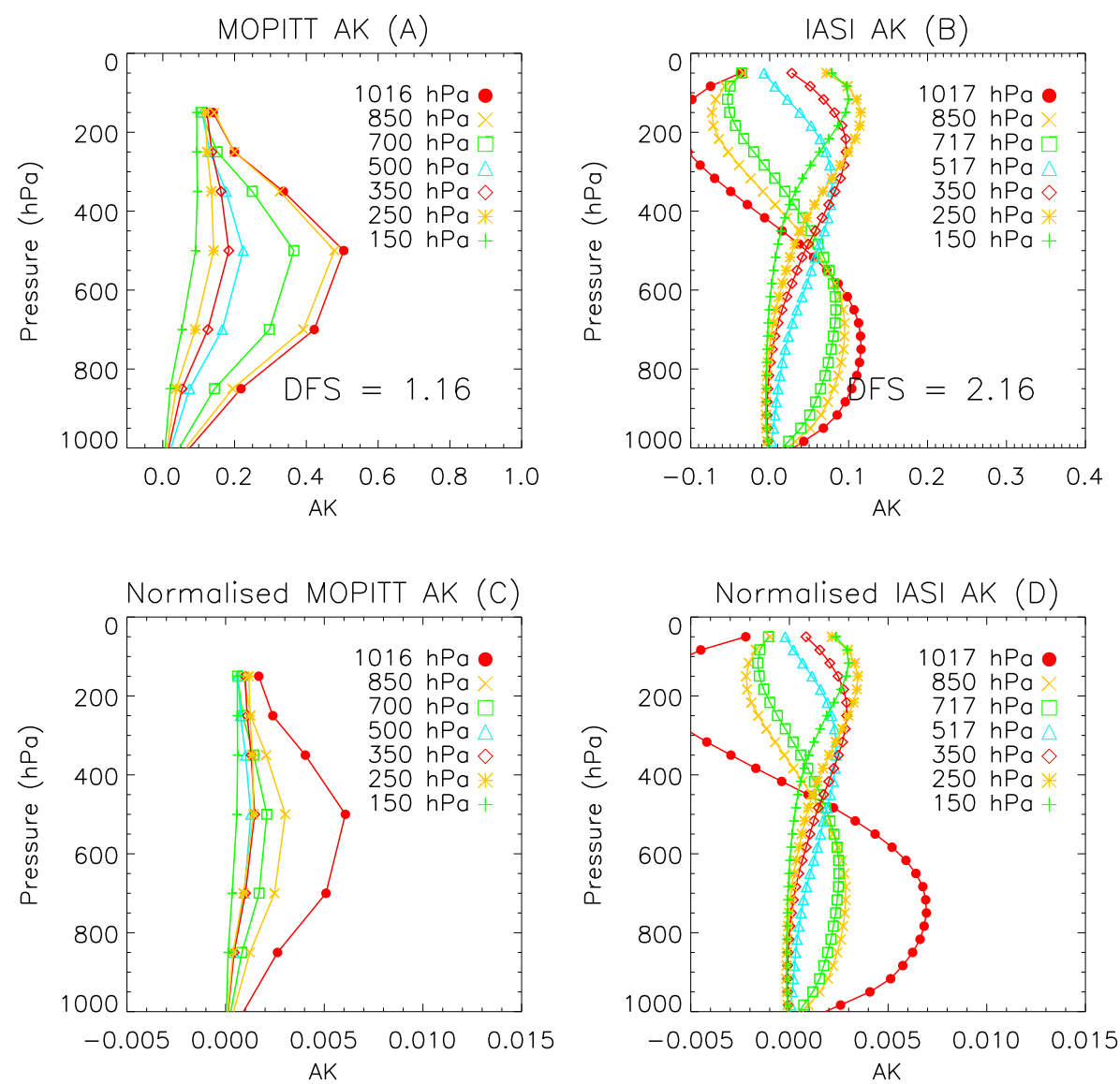

Fig. 5. Daytime and ocean averaging kernels over the Southern Africa region for 1 September 2007, for: (A) MOPITT V3 (A ${ }^{\text {MOP3 }}$ ) at

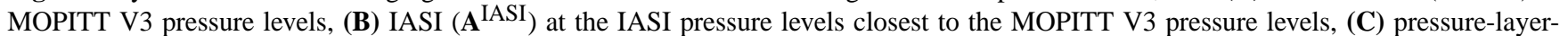
normalised averaging kernels for MOPITT V3 $\left(\mathbf{A}_{N}^{\mathrm{MOP} 3}\right)$, and (D) pressure-layer-normalised averaging kernels for IASI (A $\left.{ }_{N}^{\text {IASI }}\right)$. The units of the pressure-layer-normalised averaging kernels are $\mathrm{hPa}^{-1}$.

is an underestimate at lower pressures. The results from the intercomparison of IASI ( $\left.\boldsymbol{x}^{\mathrm{IASI}}\right)$ and MOPITT V3 $\left(\boldsymbol{x}^{\mathrm{MOP} 3}\right)$ $\mathrm{CO}$ are summarised in Table 1.

Figure $7 \mathrm{~b}$ shows the MOPITT V4 and IASI mean CO profiles and standard deviation relative to their means, at MOPITT V4 pressure levels for the 1 September 2007 over the
Southern Africa region. The differences between the two products are depicted in Fig. 7d, with large apparent discrepancies between the mean IASI and MOPITT V4 CO profiles below $800 \mathrm{hPa}$ symptomatic of the difference in the relative correlation lengths of the two different retrieval algorithms. As was discussed in Sect. 3.4 the correlation length used in 

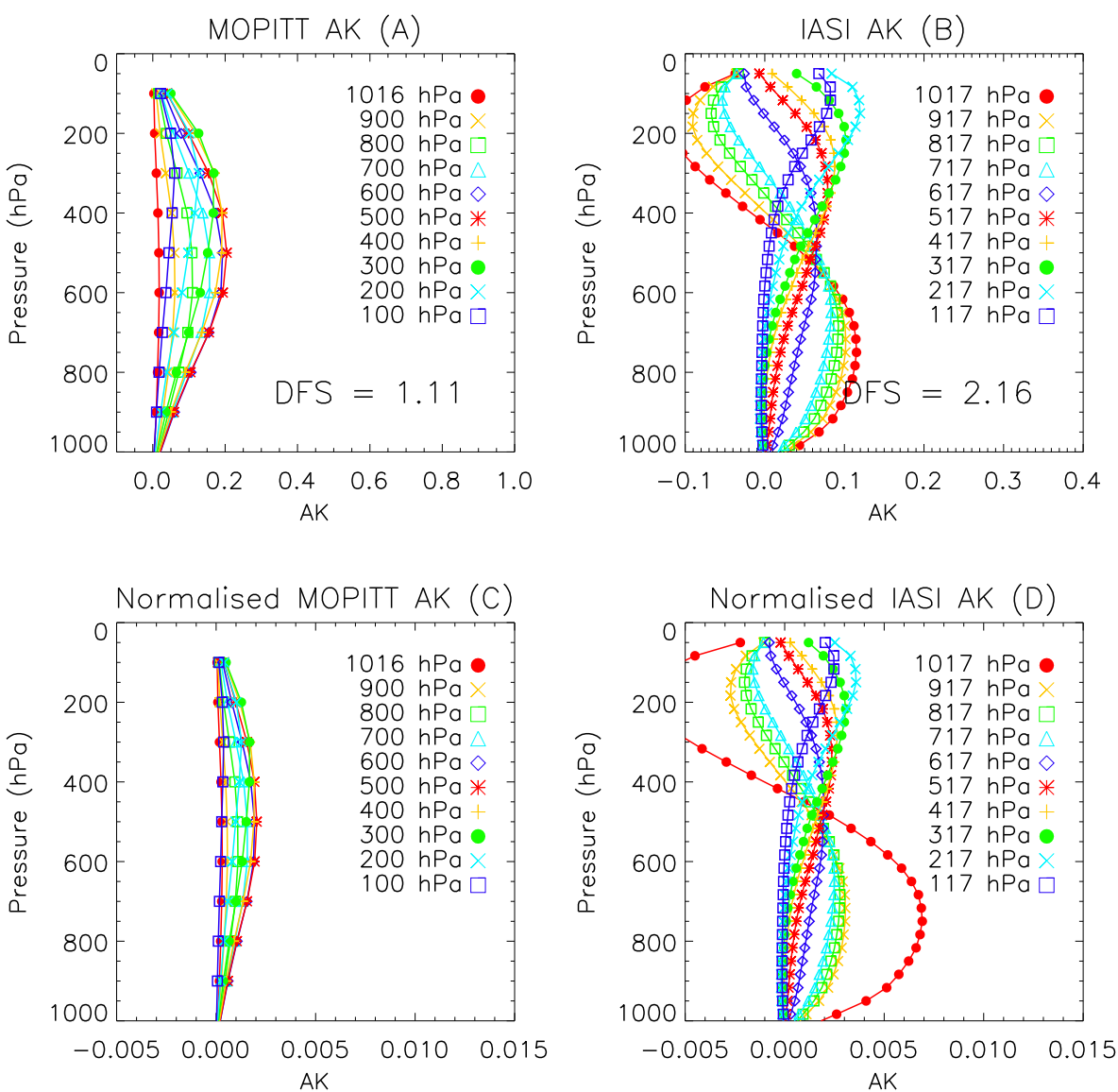

Fig. 6. Daytime and ocean averaging kernels over the Southern Africa region for 1 September 2007, for: (A) MOPITT V4 (AMOP4) at MOPITT V4 pressure levels, (B) IASI $\left(\mathbf{A}^{\mathrm{IASI}}\right)$ at the IASI pressure levels closest to the MOPITT V4 pressure levels, $(\mathbf{C})$ pressure-layernormalised averaging kernels for MOPITT V4 $\left(\mathbf{A}_{N}^{\mathrm{MOP} 4}\right)$, and $(\mathbf{D})$ pressure-layer-normalised averaging kernels for IASI $\left(\mathbf{A}_{N}^{\mathrm{IASI}}\right)$. The units of the pressure-layer-normalised averaging kernels are $\mathrm{hPa}^{-1}$.

the MOPITT V4 algorithm is $100 \mathrm{hPa}$ and the a priori profile is based on modelled data that is spatially and temporally interpolated to the retrieval scene. As the IASI retrieval scheme uses a constant a priori profile, and has a smoothing length of approximately $400 \mathrm{hPa}$ it has a greater sensitivity to mid-tropospheric events than it does to the surface (as can be seen from Figs. $5 b$ and $6 b)$. The results from the intercomparison of IASI $\left(x^{\text {IASI }}\right)$ and MOPITT V4 $\left(x^{\text {MOP4 }}\right)$ CO are summarised in Table 2.

The results presented in Fig. 7 indicate that with respect to the effect of projection of information in the mid-troposphere to the surface, the IASI retrievals more closely resemble the MOPITT V3 than the V4 retrievals. This can in part be explained by the similarity in the smoothing lengths of the IASI and MOPITT V3 a priori covariance matrices (400 and $500 \mathrm{hPa}$, respectively, in comparison to $100 \mathrm{hPa}$ for the MOPITT V4 algorithm), as well as the fact that the diagonal elements of the a priori covariance matrix are similar for IASI and MOPITT V3, in comparison to those for MOPITT V4 (see horizontal error bars in Fig. 1). It should also be noted that the differences between the MOPITT V3 and V4 retrieved profiles that can be inferred from Fig. 7 are the same as those shown in Fig. 3.

\section{Comparison of IASI and MOPITT CO using the same a priori}

It is instructive to investigate whether the differences observed between $\boldsymbol{x}^{\text {IASI }}$ and $\boldsymbol{x}^{\text {MOP }}$ are due to the choice of a priori used by each of the retrieval schemes. A useful way to examine this problem, is to use the same a priori profile and covariance for both the MOPITT and IASI retrievals. In order to do this the IASI a priori profiles and covariance matrices were integrated into the MOPITT V3 and V4 retrieval algorithms.

The differences between the IASI ( $\left.\boldsymbol{x}^{\mathrm{IASI}}\right)$ and "adjusted" MOPITT $\left(x^{\mathrm{MOP}^{\prime}}\right)$ profiles shown in Fig. 8c are similar to the differences between the IASI and MOPITT V3 profiles (Fig. 7c), which is to be expected given the similarities in 

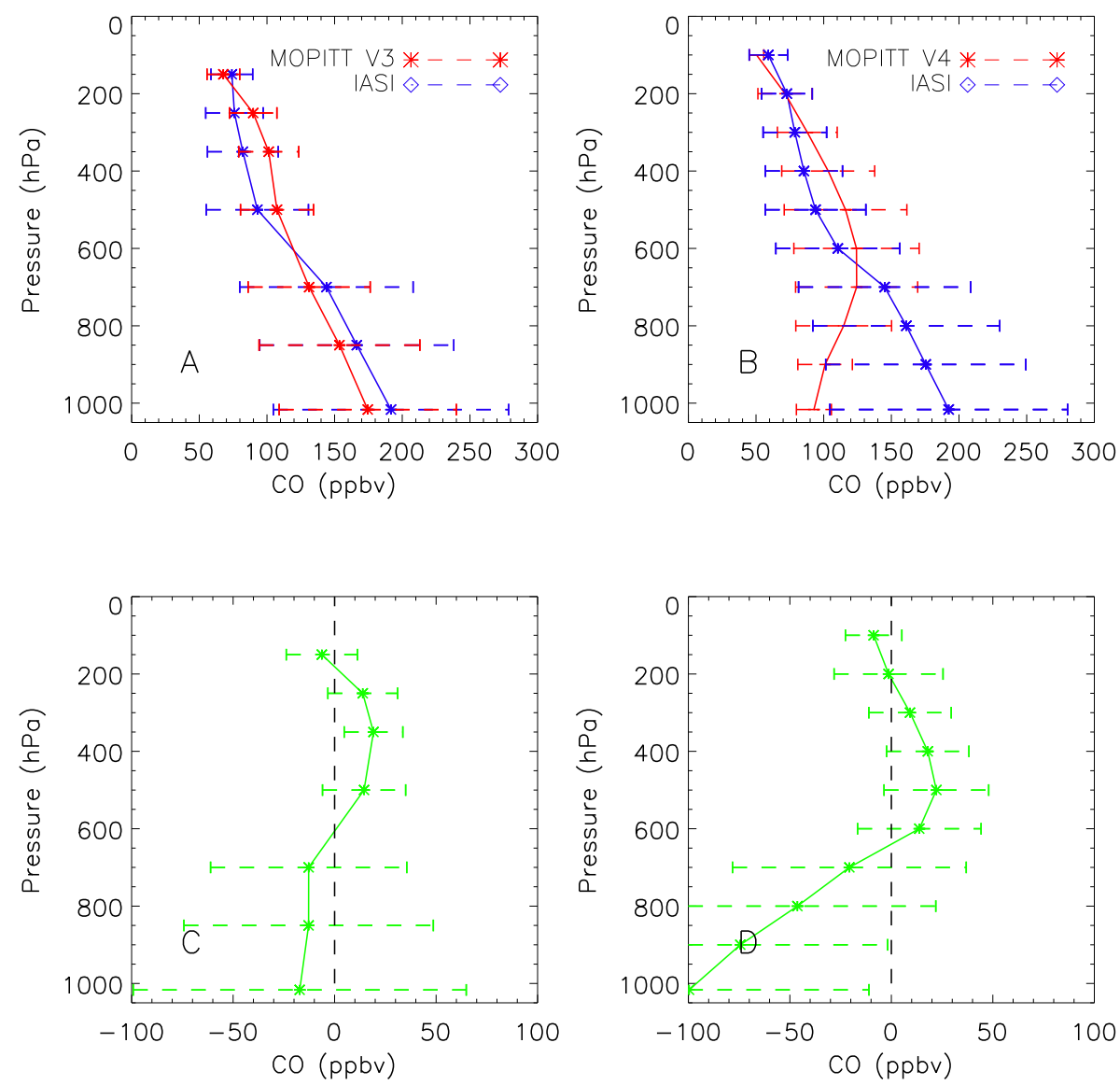

Fig. 7. (A) MOPITT V3 and IASI CO mean profiles (solid red line and blue line, respectively) and standard deviation relative to their means (dashed lines), (B) MOPITT V4 and IASI CO mean profiles (solid red line and blue line, respectively) and standard deviation relative to their means (dashed lines), (C) the mean difference between MOPITT V3 CO and IASI CO (solid green line) and the standard deviation (dashed green line) relative to the mean, and (D) the mean difference between MOPITT V4 CO and IASI CO (solid green line) and the standard deviation (dashed green line) relative to the mean. The IASI CO retrievals closest to the MOPITT pressure levels are used here, and all comparisons are for over the ocean and during the daytime of 1 September 2007, over the Southern Africa region.

the smoothing length and a priori covariance matrices of the IASI and MOPITT V3 retrieval algorithms. Figure 8d also demonstrates that $\boldsymbol{x}^{\mathrm{IASI}}$ and $\boldsymbol{x}^{\mathrm{MOP} 4^{\prime}}$ are in better agreement, particularly in the lower troposphere, compared to the differences between $x^{\mathrm{IASI}}$ and $\boldsymbol{x}^{\mathrm{MOP} 4}$ (Fig. 7d). This result is mainly explained by the fact that both retrievals now use the same a priori statistics, in particular utilising an identical correlation length, meaning that the surface retrievals are equally affected by the influence of mid-tropospheric events. The results from the intercomparison between the IASI and adjusted MOPITT V3 and V4 CO products are summarised in Tables 1 and 2 respectively. This better agreement corresponds well with other studies (e.g. Luo et al., 2007; Ho et al., 2009; Warner et al., 2007), which also investigated the effect of minimising the differences in the a priori statistics, in the intercomparison of different retrieval products.

Whilst the IASI and MOPITT products have now been retrieved using the same a priori information, there still exist differences in the measurement sensitivity, i.e. weighting functions and noise, of the retrievals. The retrieved state vector can be written as a weighted mean of the true profile $\left(\boldsymbol{x}_{\text {true }}\right)$ and the a priori profile $\left(\boldsymbol{x}_{\mathrm{a}}\right)$ (Rodgers and Connor, 2003). In the case of IASI retrievals this can be written as:

$\boldsymbol{x}^{\mathrm{IASI}}=\mathrm{A}^{\mathrm{IASI}}\left(\boldsymbol{x}_{\text {true }}-\boldsymbol{x}_{\mathrm{a}}^{\mathrm{IASI}}\right)+\boldsymbol{x}_{\mathrm{a}}^{\mathrm{IASI}}+\boldsymbol{\epsilon}^{\mathrm{IASI}}$,

whilst for the MOPITT retrievals (V3 and V4):

$\boldsymbol{x}^{\mathrm{MOP}}=\mathrm{A}^{\mathrm{MOP}}\left(\boldsymbol{x}_{\text {true }}-\boldsymbol{x}_{\mathrm{a}}^{\mathrm{MOP}}\right)+\boldsymbol{x}_{\mathrm{a}}^{\mathrm{MOP}}+\boldsymbol{\epsilon}^{\mathrm{MOP}}$,

where $\epsilon$ represents the error in the retrieved profiles due to both random and systematic errors in the measured signal and in the algorithm's forward model (Rodgers and Connor, 2003). By processing the MOPITT retrieval algorithms using the IASI a priori, the modified MOPITT retrieved CO profile, $x^{\mathrm{MOP}^{\prime}}$, can be written as:

$\boldsymbol{x}^{\mathrm{MOP}^{\prime}}=\mathbf{A}^{\mathrm{MOP}^{\prime}}\left(\boldsymbol{x}_{\text {true }}-\boldsymbol{x}_{\mathrm{a}}^{\mathrm{IASI}}\right)+\boldsymbol{x}_{\mathrm{a}}^{\mathrm{IASI}}+\boldsymbol{\epsilon}^{\mathrm{MOP}^{\prime}}$, 

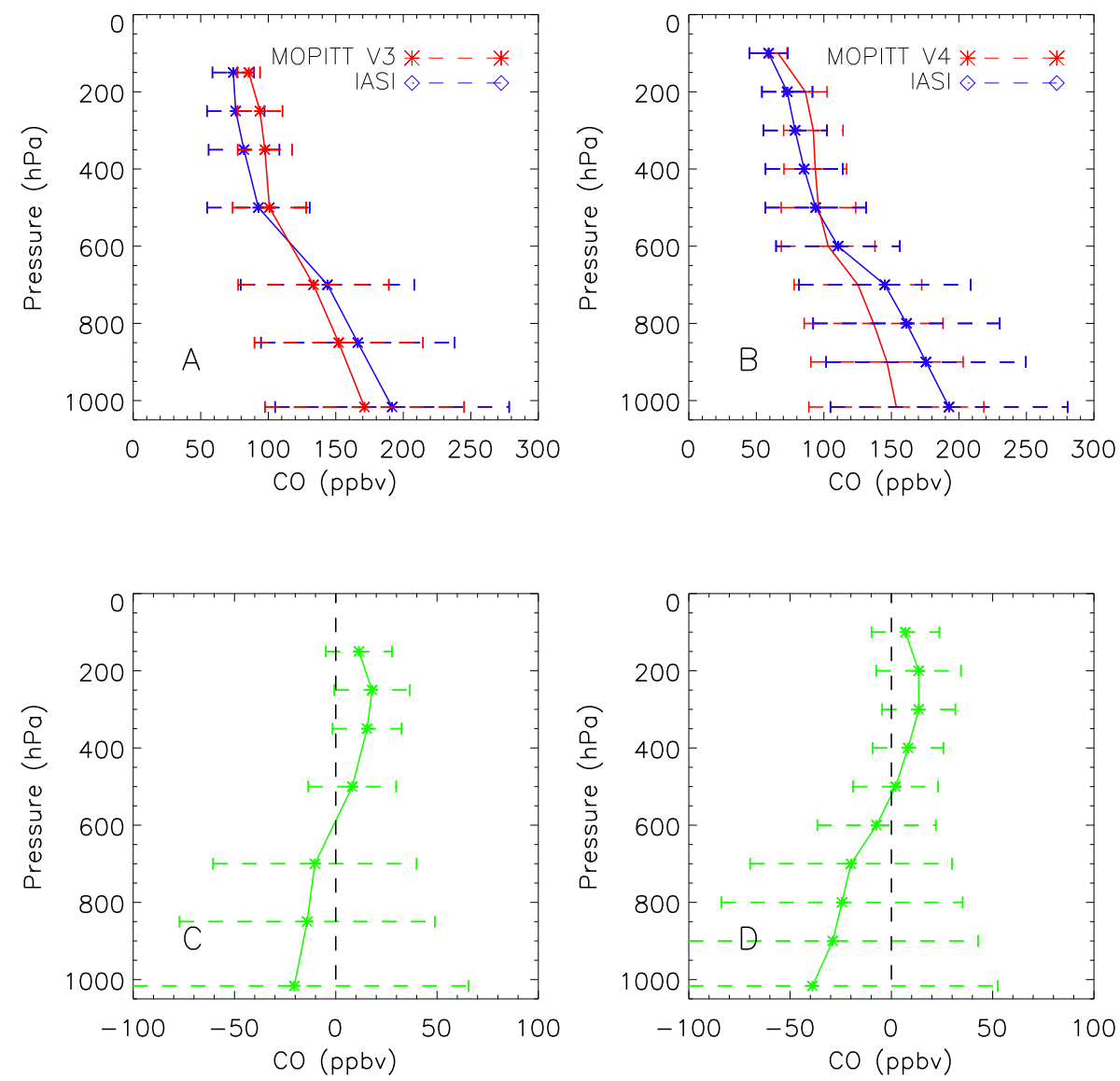

Fig. 8. Comparison of retrievals performed with the same a priori (ULIRS profile and error covariances), $\boldsymbol{x}^{\mathrm{MOP}^{\prime}}$ and $\boldsymbol{x}^{\mathrm{IASI}}$ : (A) adjusted MOPITT V3 and IASI CO mean profiles; (B) adjusted MOPITT V4 and IASI CO mean profiles; $(\mathbf{C})$ the mean difference between adjusted MOPITT V3 CO and IASI CO profiles; and (D) the mean difference between adjusted MOPITT V4 CO and IASI CO profiles. All comparisons are for over the ocean and during the daytime of 1 September 2007, over the Southern Africa region.

where $\mathbf{A}^{\mathrm{MOP}^{\prime}}$ represents the adjusted MOPITT (V3 and V4) averaging kernel matrices.

Differences between $\boldsymbol{x}^{\mathrm{IASI}}$ and $\boldsymbol{x}^{\mathrm{MOP}^{\prime}}$ can be characterised from Eqs. (4) and (6). Further insight into differences in the smoothing effect of the two retrievals (the smoothing bias) can be obtained by examining what happens when the averaging kernels for each instrument are applied to a "true" profile (thus simulating the effect of retrieval characteristics on the retrieved profiles).

A further step forward can be made by considering what would be obtained if the averaging kernels are applied to realistic true profiles. For this study the truth is represented by gridded output from the GEOS-Chem (v7.04.10) CTM (Bey et al., 2001 and http://www.GEOS-Chem.org/), driven by meteorological observations from the Goddard Earth Observing System v5 (GEOS-5) from the Global Modeling and Assimilation Office Global Circulation model based at NASA Goddard. The GEOS-Chem global 3-D CTM relates surface emissions of $\mathrm{CO}$ to global 3-D distributions of $\mathrm{CO}$ concentration. Primary sources of $\mathrm{CO}$ include biomass burning, fossil and biofuel combustion. Secondary sources are from the oxidation of co-emitted Volatile Organic Compounds (VOCs). We use surface biomass burning emission estimates from the Global Fire Emission Database (GFED version 2) (Van Der Werf et al., 2006), and the model is used in tagged $\mathrm{CO}$ tracer mode at a horizontal resolution of $2^{\circ} \times 2.5^{\circ}$, with 47 sigma levels that span the surface to $0.01 \mathrm{hPa}$. The 3-D meteorological data is updated every six hours, and boundary layer and tropopause heights are updated every three hours. We use GEOS-Chem CO profiles, $x^{\mathrm{GEOS}}$, with the closest $\boldsymbol{x}^{\mathrm{GEOS}}$ to the collocated IASI and adjusted MOPITT CO profiles being used for this comparison; the GEOS-Chem total column densities for the studied region are shown in Fig. 4d.

$\boldsymbol{x}_{\text {MODEL }}^{\mathrm{IASI}}$ and $\boldsymbol{x}_{\text {MODEL }}^{\mathrm{MOP}^{\prime}}$ have been calculated from Eqs. (4) and (6), respectively, with $x_{\text {true }}$ given by $x^{\mathrm{GEOS}}$. In the absence of any other biases, $\boldsymbol{x}_{\text {MODEL }}^{\text {MOP' }}$ and $\boldsymbol{x}_{\text {MODEL }}^{\text {IASI }}$ represent the "best possible" retrieval of the GEOS-Chem profiles by the adjusted MOPITT and IASI algorithms, respectively. The results from the intercomparison between the expected 

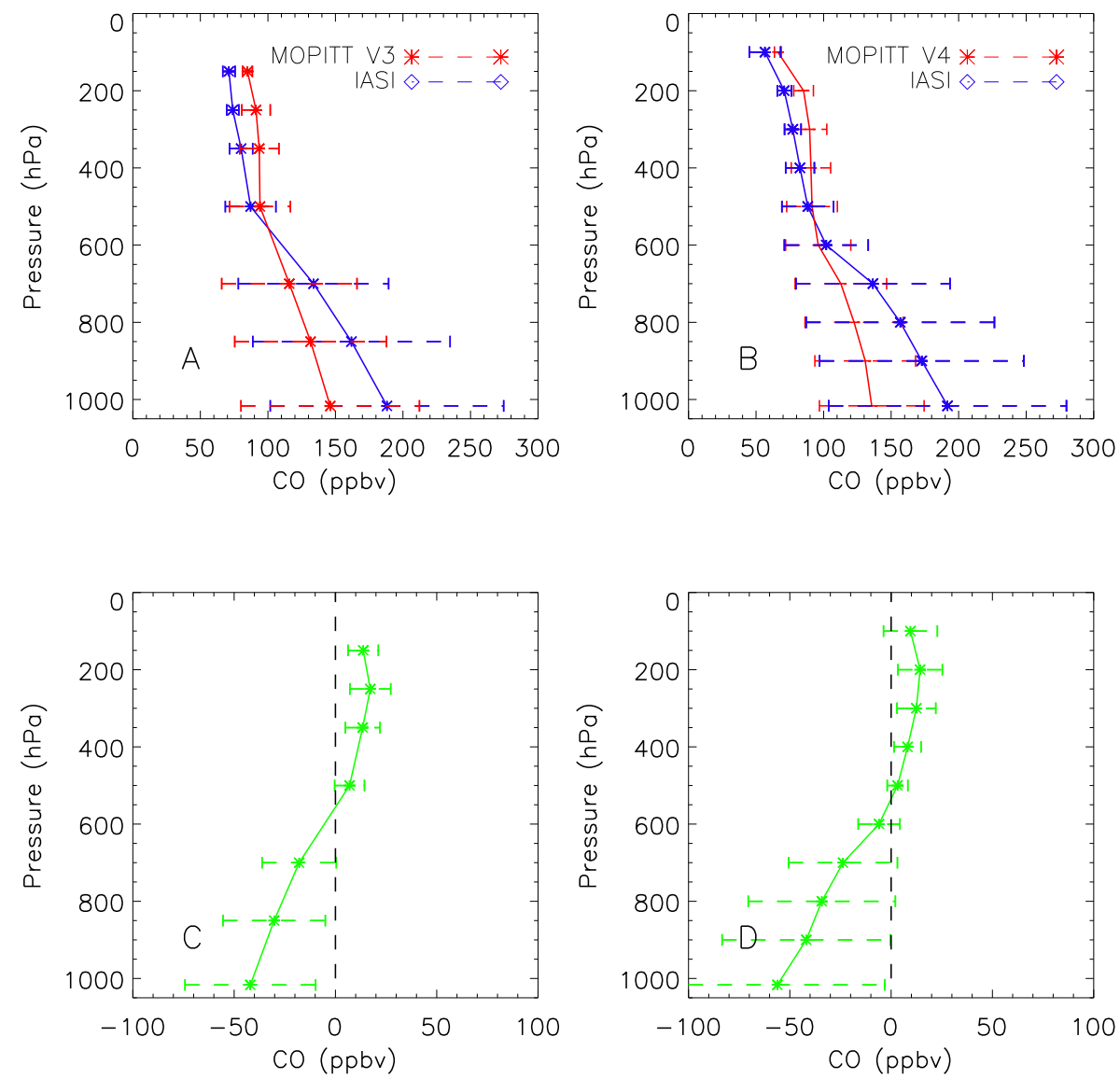

Fig. 9. Same as Fig. 8, except for $\boldsymbol{x}_{\text {MODEL }}^{\text {MOP' }}$ and $\boldsymbol{x}_{\text {MODEL }}^{\text {IASI }}$ : (A) adjusted MOPITT V3 and IASI CO mean profiles; (B) adjusted MOPITT V4 and IASI CO mean profiles; (C) the mean difference between adjusted MOPITT V3 CO and IASI CO profiles; and (D) the mean difference between adjusted MOPITT V4 CO and IASI CO profiles. (A) and (B) are in relation to the retrieval of a true profile, as provided by GEOS-Chem. All comparisons are for over the ocean and during the daytime of 1 September 2007, over the Southern Africa region.

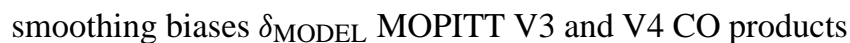
are summarised in Tables 1 and 2 respectively.

As can be seen from Figs. 8 and 9, and also from Tables 1 and 2 , in the upper atmosphere the differences between $\boldsymbol{x}_{\mathrm{MODEL}}^{\mathrm{MOP}}$ and $\boldsymbol{x}_{\mathrm{MODEL}}^{\mathrm{IASI}}$ are of a very similar magnitude to those that are observed between $x^{\mathrm{IASI}}$ and $\boldsymbol{x}^{\mathrm{MOP}^{\prime}}$. In the lower levels of the atmosphere the differences between $\boldsymbol{x}_{\text {MODEL }}^{\mathrm{MOP}^{\prime}}$ and $\boldsymbol{x}_{\text {MODEL }}^{\mathrm{IASI}}$ are greater than those observed between $\boldsymbol{x}^{\mathrm{IASI}}$ and $\boldsymbol{x}^{\mathrm{MOP}^{\prime}}$, a result which is also reflected in the differences between the total columns (see Tables 1 and 2). This result shows that in the upper atmosphere the differences between the IASI and MOPITT CO concentrations are as expected, given the smoothing bias, but that in the lower atmosphere the IASI and MOPITT retrievals agree better than expected given the smoothing bias. It is hypothesised that this is a result of the increased sensitivity of the instruments at the lower atmospheric levels. Retrieving GEOSChem modelled profiles in this manner has therefore shown that many of the observed differences between the IASI and adjusted MOPITT retrievals can mostly be explained by the smoothing bias.

\section{Comparison with reduced smoothing error}

The results of Sect. 5 indicate that the differences between $\boldsymbol{x}^{\mathrm{MOP}^{\prime}}$ and $\boldsymbol{x}^{\mathrm{IASI}}$ are a result of the smoothing bias. The direct comparison between the products includes a contribution from smoothing error, even when the same a priori is used for the retrievals of both instruments to be compared. This arises from the non-identical weighting functions and error covariances of the two instruments. Rodgers and Connor (2003) proposed a methodology, also employed by Luo et al. (2007); Warner et al. (2007); Ho et al. (2009), in which the averaging kernels of one retrieval scheme are used to smooth the retrieved data set from the other set of measurements, providing that both retrievals utilise the same set of a priori statistics. With the caveat that this "double smoothing" of the truth will serve to smooth away some of the intrinsic information 

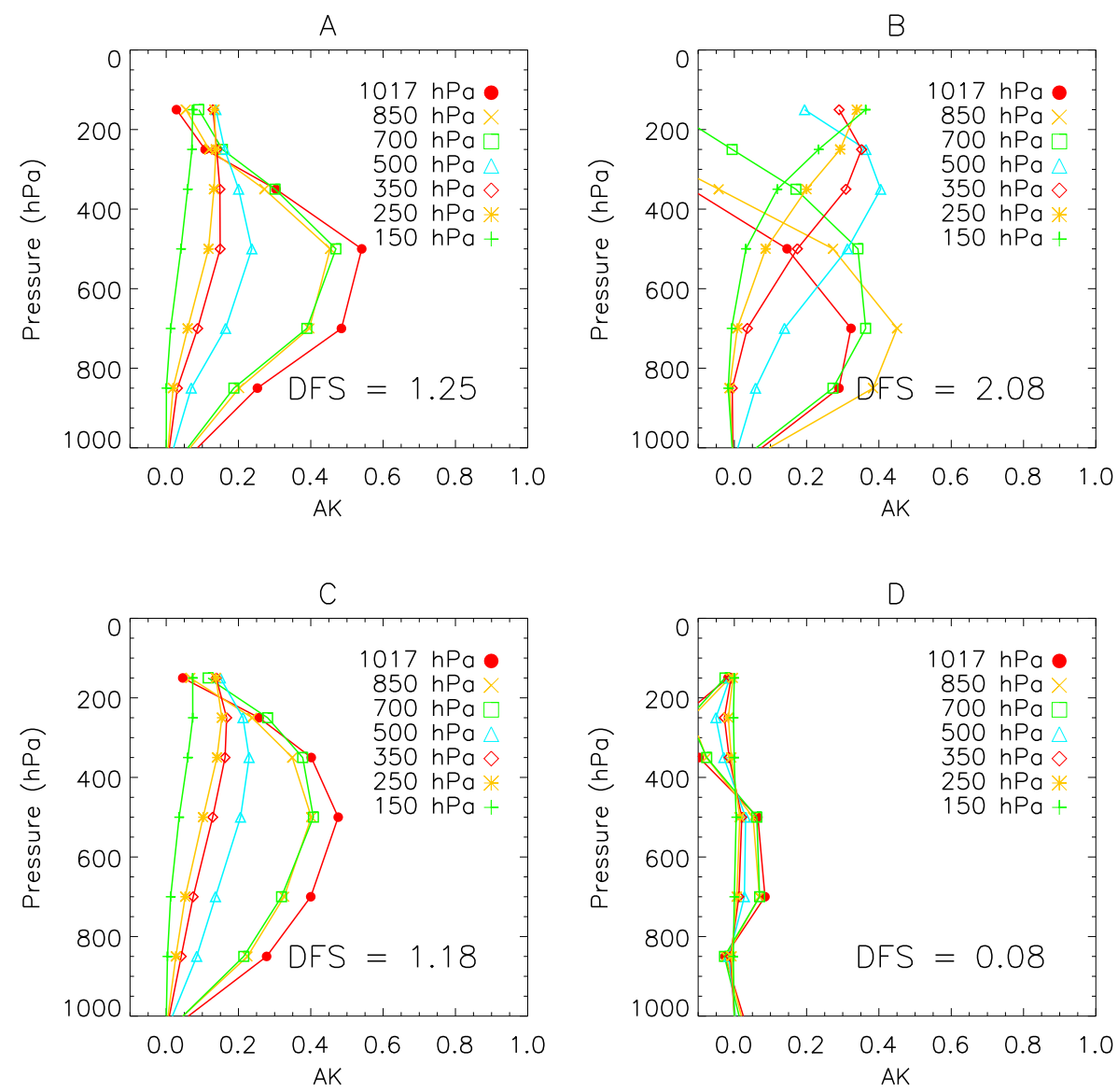

Fig. 10. Daytime and ocean averaging kernels over the Southern Africa region for 1 September 2007, for: (A) Adjusted MOPITT V3 averaging kernels converted onto the IASI pressure grid $\mathbf{A}^{\mathrm{MOP} 3^{\prime \prime}} ;(\mathbf{B})$ IASI averaging kernels at pressure levels closest to the MOPITT V3 pressure levels $\mathbf{A}^{\mathrm{IASI}} ;$ (C) $\mathbf{A}^{\mathrm{MOP} 3^{\prime \prime}} \mathbf{A}^{\mathrm{IASI}}$; and (D) $\mathbf{A}^{\mathrm{MOP} 3^{\prime \prime}}-\mathbf{A}^{\mathrm{MOP} 3^{\prime \prime}} \mathbf{A}^{\mathrm{IASI}}$.

contained within the retrieved data set, this section discusses such a method, the justification for its use, and the results that are obtained. In particular we note that the real importance here is to show that quantities can be calculated which minimise smoothing contributions. In this case, it is also important that the a priori is appropriate ("near optimal") for the region concerned.

\subsection{Methodology}

Rodgers and Connor (2003) showed that the effect of smoothing error in a comparison can be reduced if the retrieval of one instrument is simulated using the retrieval of another. For profiles used in this study, the number of DFS for the MOPITT retrievals were found to be comparable to, yet usually smaller than, that of IASI. The DFS for IASI over the oceanic Southern Africa region during the daytime were found to range from 1.34 to 2.53 , whereas those corresponding to $A^{\mathrm{MOP3}{ }^{\prime}}$ and $A^{\mathrm{MOP}^{\prime}}$ were found to range from 0.99 to 2.29 and from 0.95 to 2.00 , respectively.
Providing that common a priori statistics are used in the retrievals, Rodgers and Connor (2003) states that:

$\boldsymbol{x}^{\mathrm{IASI}}=\mathbf{A}^{\mathrm{MOP}^{\prime \prime}}\left(\boldsymbol{x}_{\mathrm{IASI}}-\boldsymbol{x}_{\mathrm{a}}^{\mathrm{IASI}}\right)+\boldsymbol{x}_{\mathrm{a}}^{\mathrm{IASI}}$,

where $\mathbf{A}^{\mathrm{MOP}^{\prime \prime}}$ is $\mathbf{A}^{\mathrm{MOP}^{\prime}}$, but converted onto the same pressure grid (via simple interpolation) as that used by IASI, and $\boldsymbol{x}^{\text {IASI' }}$ now represents the retrieved IASI profile, smoothed using $\mathbf{A}^{\mathrm{MOP}^{\prime \prime}}$. The IASI retrieval should be optimal with respect to the comparison ensemble, which it is expected to be because the IASI a priori were specifically constructed for the comparison ensemble. Hence this relatively simple equation from Rodgers and Connor (2003) may be used.

From Eqs. (4), (6), and (7), the difference between $x^{\mathrm{IASI}^{\prime}}$ and $\boldsymbol{x}^{\mathrm{MOP}^{\prime}}$ can be written as:

$$
\begin{aligned}
\boldsymbol{x}^{\mathrm{MOP}^{\prime \prime}}-\boldsymbol{x}^{\mathrm{IASI}^{\prime}}=\left(\mathrm{A}^{\mathrm{MOP}^{\prime \prime}}-\mathbf{A}^{\mathrm{MOP}^{\prime \prime}} \mathbf{A}^{\mathrm{IASI}}\right) \\
\left(x_{\text {true }}-\boldsymbol{x}_{\mathrm{a}}^{\mathrm{IASI}}\right)+\epsilon^{\mathrm{MOP}^{\prime}}-\mathbf{A}^{\mathrm{MOP}^{\prime \prime}} \epsilon^{\mathrm{IASI}} .
\end{aligned}
$$

Providing that the $\mathbf{A}^{\mathrm{MOP}^{\prime}}-\mathbf{A}^{\mathrm{MOP}^{\prime}} \mathbf{A}^{\mathrm{IASI}}$ term is small, Eq. (8) should represent the difference between the MOPITT 
A
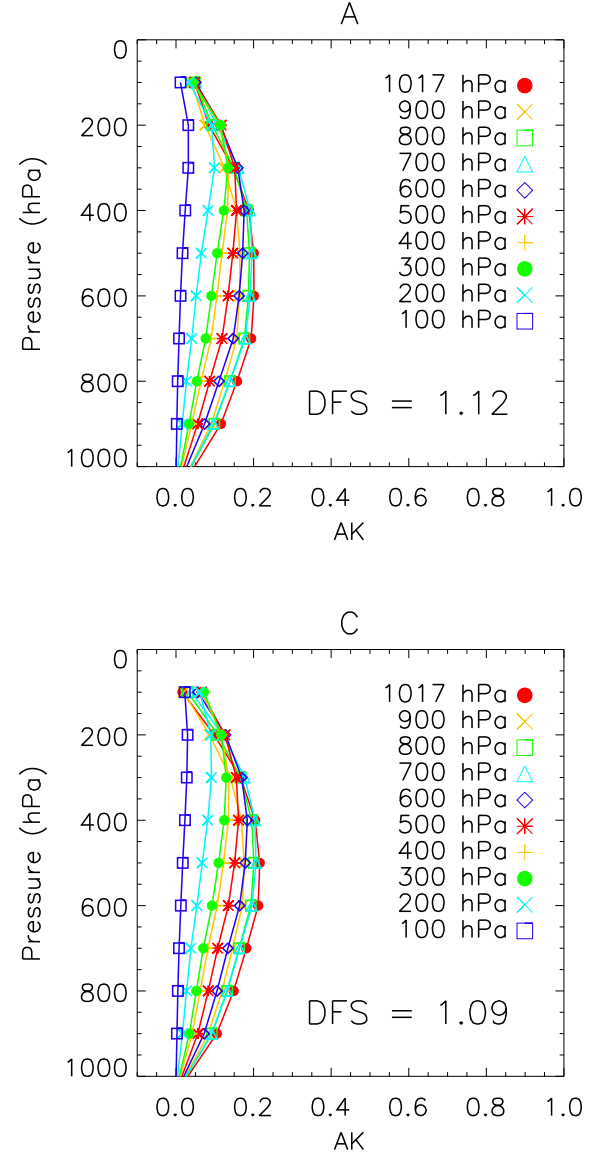
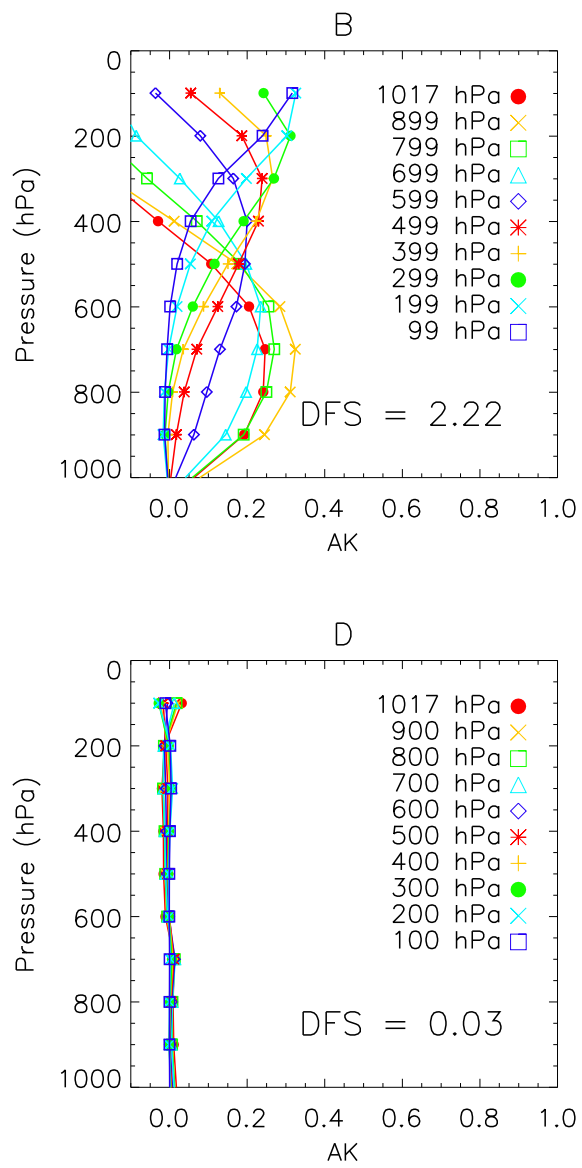

Fig. 11. Same as Fig. 10, but for MOPITT V4. All comparisons are for over the ocean and during the daytime of 1 September 2007, over the Southern Africa region.

systematic error and the vertical IASI smoothed systematic error. As can be seen from Figs. 10 and 11, the DFS for $\mathbf{A}^{\mathrm{MOP}^{\prime \prime}}-\mathbf{A}^{\mathrm{MOP}} \mathbf{A}^{\mathrm{IASI}}$ are on average 0.08 and 0.03 for the MOPITT V3 and V4 retrievals, respectively. As this difference quantity is larger for the MOPITT V3 comparisons, it makes the results of $\boldsymbol{x}^{\mathrm{MOP}^{\prime \prime}}-\boldsymbol{x}^{\mathrm{IASI}}$ more difficult to interpret than for the corresponding IASI and V4 analysis.

\subsection{Results}

Application of the above process to a representative true profile is important in order to demonstrate that the smoothing error terms have been very much reduced. Again, GEOSChem $\mathrm{CO}$ profiles, were used for this comparison, with the smoothing bias now represented by $\delta_{\text {MODEL}^{\prime}}$. It should be noted that $\delta_{\text {MODEL }^{\prime}}$ represents the expected smoothing bias for $\boldsymbol{x}^{\mathrm{IASI}^{\prime}}$ and $\boldsymbol{x}^{\mathrm{MOP}^{\prime}}$, whilst $\delta_{\text {MODEL }}$ represents the expected smoothing bias for $\boldsymbol{x}^{\mathrm{IASI}}$ and $\boldsymbol{x}^{\mathrm{MOP}}$. As can be seen from Fig. 13, the smoothing error across the profiles, in the case of both the MOPITT V3 and V4 comparisons is small. By comparing Figs. 13 and 9 it can be seen that the application of Eq. (7) has significantly reduced the expected smoothing bias.
Figure 12 compares the mean values for $\boldsymbol{x}^{\mathrm{IASI}^{\prime}}, \boldsymbol{x}^{\mathrm{MOP} 3^{\prime}}$, and $\boldsymbol{x}^{\mathrm{MOP}^{\prime}}-\boldsymbol{x}^{\mathrm{IASI}^{\prime}}$, for each MOPITT V3 pressure level for 1 September 2007 for the daytime over the oceanic Southern Africa region. An offset between the total column densities of $6.4 \%$ was also computed, and a correlation coefficient between the IASI and MOPITT V3 total columns of 0.86 is comparable to the correlation coefficient between the IASI operational and MOPITT V3 column amounts of 0.87 that was observed by George et al. (2009). Over ocean and during the daytime, the MOPITT V3 CO profile appears to be an overestimate of the IASI retrieved profile in the mid-lower troposphere.

Figure 12 also compares the mean values for $\boldsymbol{x}^{\mathrm{IASI}^{\prime}}$, $\boldsymbol{x}^{\mathrm{MOP} 4^{\prime}}$, and $\boldsymbol{x}^{\mathrm{MOP}^{\prime}}-\boldsymbol{x}^{\mathrm{IASI}^{\prime}}$, for each MOPITT V4 pressure level. As can be seen from this figure, there is excellent agreement between $\boldsymbol{x}^{\mathrm{IASI}^{\prime}}$ and $\boldsymbol{x}^{\mathrm{MOP} 4^{\prime}}$ across the profile. The results of the comparison between the adjusted MOPITT V4 and the smoothed IASI products are summarised in Table 2. The agreement between the smoothed IASI and adjusted MOPITT V4 total column densities is also high (with a mean absolute difference of $2.9 \%$ ), and there is a correlation coefficient between the column amounts for $\boldsymbol{x}^{\mathrm{IASI}^{\prime}}$ and 

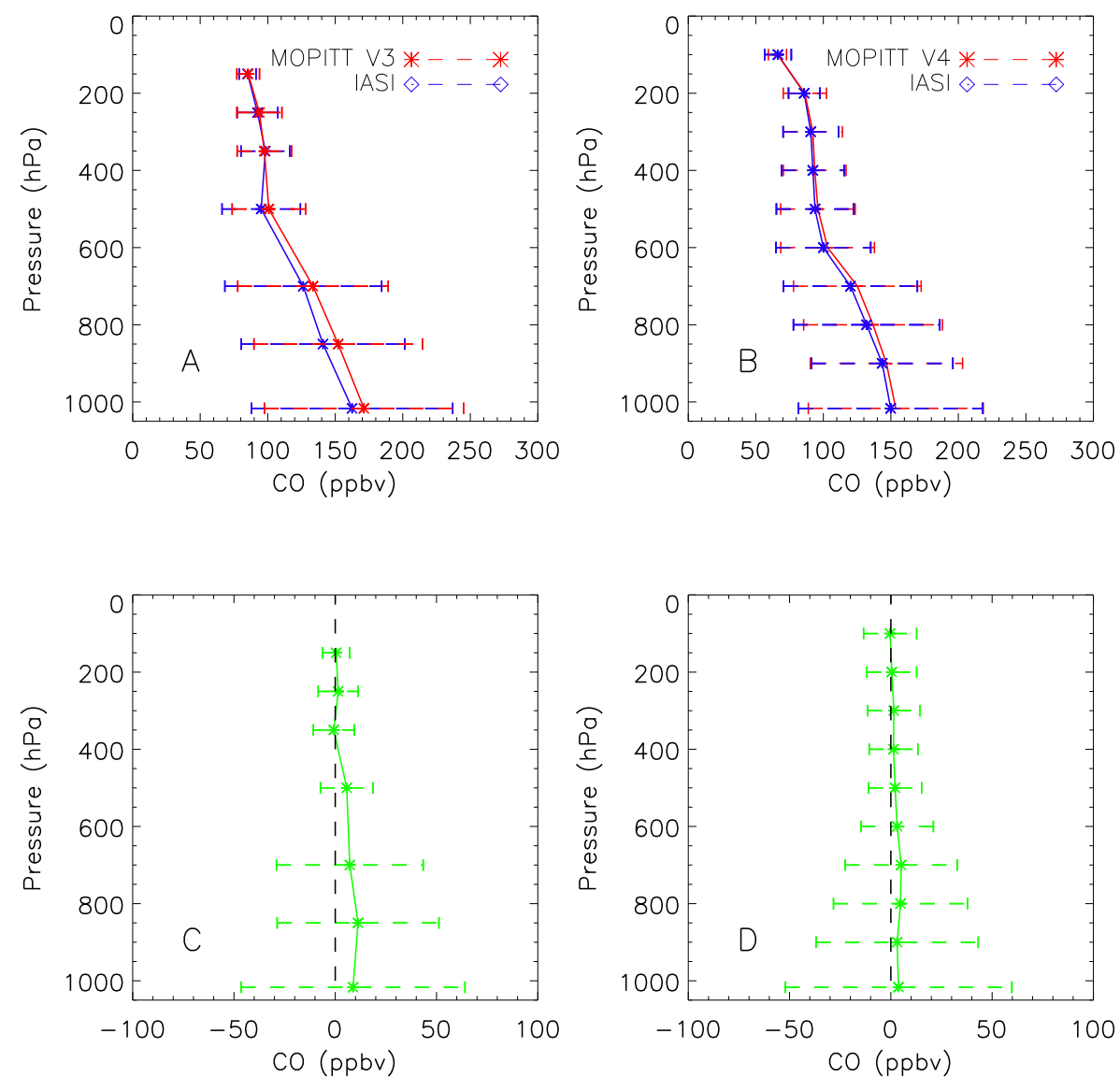

Fig. 12. with reduced smoothing error using the derived quantity in Eq. (7), $\boldsymbol{x}^{\mathrm{MOP}^{\prime}}$ and $\boldsymbol{x}^{\mathrm{IASI}^{\prime}}$ : (A) adjusted MOPITT V3 and MOPITTsmoothed IASI CO mean profiles; (B) adjusted MOPITT V4 and MOPITT-smoothed IASI CO mean profiles; (C) the mean difference between adjusted MOPITT V3 CO and MOPITT-smoothed IASI CO profiles; and (D) the mean difference between adjusted MOPITT V4 CO and MOPITT-smoothed IASI CO profiles. All comparisons are for over the ocean and during the daytime of 1 September 2007, over the Southern Africa region.

$x^{\mathrm{MOP}^{\prime}}$ of 0.86 . The results of this comparison indicate that for the data studied, over ocean and during the daytime, the IASI and MOPITT V4 data sets are in very good agreement.

Tables 3 and 4 summarise the values for $\boldsymbol{x}^{\mathrm{MOP}^{\prime}}-\boldsymbol{x}^{\mathrm{IASI}^{\prime}}$, along with the expected smoothing bias $\left(\delta_{\mathrm{MODEL}^{\prime}}\right)$ for the 1 September 2007 over the region shown in Fig. 4 for the daytime/ocean, nighttime/ocean, and nighttime/land scenarios. The results for the daytime/land scenario are not shown as there were insufficient coincident data points from which to draw conclusions from. It should also be noted that only profiles for which there were retrieved values at each of the fixed MOPITT pressure levels were chosen, and as much of the Southern Africa land region has a surface pressure of less than $900 \mathrm{hPa}$ (but greater than $850 \mathrm{hPa}$ ) this resulted in a large discrepancy in the number of MOPITT V3 and V4 comparisons over land during the nighttime. The comparisons for the true profiles show that for V4 data, the anticipated differences are very small after adjustment for the a priori. Therefore, any biases observed are likely to be intrinsic, non-retrieval, systematic biases between MOPITT and IASI, which on average across the profile appear to be less than $4 \%$ and are always less than $7 \%$, allowing for the modelled expected differences. The total column bias between the two instruments, again allowing for model computed differences, is always less than $5.5 \%$. The results for $\mathrm{V} 3$ are less easy to interpret but would be consistent with systematic biases of up to $10 \%$. It should be noted that of the three data sets (IASI, MOPITT V3, MOPITT V4), the MOPITT V3 observes the highest CO load for the region of study. As the MOPITT V4 product has been shown to be more reliable than the MOPITT V3 product (see e.g. Deeter et al., 2010), it is encouraging that ULIRS agrees to such a large extent with the MOPITT V4 data set. 
Table 3. $\delta \boldsymbol{x}_{\mathrm{BIAS}}$ for IASI and MOPITT V3 CO retrievals for different scenarios.

\begin{tabular}{|c|c|c|c|c|c|c|}
\hline & \multicolumn{2}{|c|}{ day and ocean } & \multicolumn{2}{|c|}{ night and ocean } & \multicolumn{2}{|c|}{ night and land } \\
\hline & $x^{\mathrm{MOP}^{\prime}}-x^{\mathrm{IASI}^{\prime}}(N=972)$ & $\delta_{\text {MODEL }^{\prime}}(N=972)$ & $x^{\mathrm{MOP}^{\prime}}-x^{\mathrm{IASI}^{\prime}}(N=908)$ & $\delta_{\text {MODEL }^{\prime}}(N=908)$ & $x^{\mathrm{MOP}^{\prime}}-x^{\mathrm{IASI}^{\prime}}(N=711)$ & $\delta_{\text {MODEL }^{\prime}}(N=710)$ \\
\hline \multicolumn{7}{|l|}{$850 \mathrm{hPa}$} \\
\hline Mean (ppv) & $11.2(39.1)$ & $7.3(14.6)$ & $11.5(38.8)$ & $1.2(7.4)$ & $28.7(44.1)$ & $19.1(29.7)$ \\
\hline Bias (\%) & $8.0(27.8)$ & $5.9(11.8)$ & $9.7(32.9)$ & $1.1(7.0)$ & $15.8(24.3)$ & $11.4(17.7)$ \\
\hline \multicolumn{7}{|l|}{$500 \mathrm{hPa}$} \\
\hline Mean (ppv) & $5.7(12.8)$ & $3.6(5.5)$ & $12.0(8.1)$ & $1.2(2.8)$ & $8.6(13.1)$ & $-0.6(5.6)$ \\
\hline Bias $(\%)$ & $5.8(13.4)$ & $4.1(6.3)$ & $15.2(10.2)$ & $1.6(3.7)$ & $8.3(12.5)$ & $-0.7(6.0)$ \\
\hline \multicolumn{7}{|l|}{$250 \mathrm{hPa}$} \\
\hline Mean (ppv) & $1.5(8.8)$ & $1.5(2.1)$ & $6.3(13.4)$ & $-0.1(1.5)$ & $7.5(11.0)$ & $-1.5(4.9)$ \\
\hline Bias $(\%)$ & $1.6(9.5)$ & $1.7(2.4)$ & $7.6(16.3)$ & $-0.1(1.8)$ & $8.0(11.8)$ & $-1.7(5.7)$ \\
\hline \multicolumn{7}{|l|}{ Total column } \\
\hline Absolute Bias (\%) & $6.4(17.5)$ & $4.0(7.3)$ & $10.4(14.4)$ & $0.8(4.4)$ & $13.0(14.9)$ & $3.7(6.7)$ \\
\hline
\end{tabular}
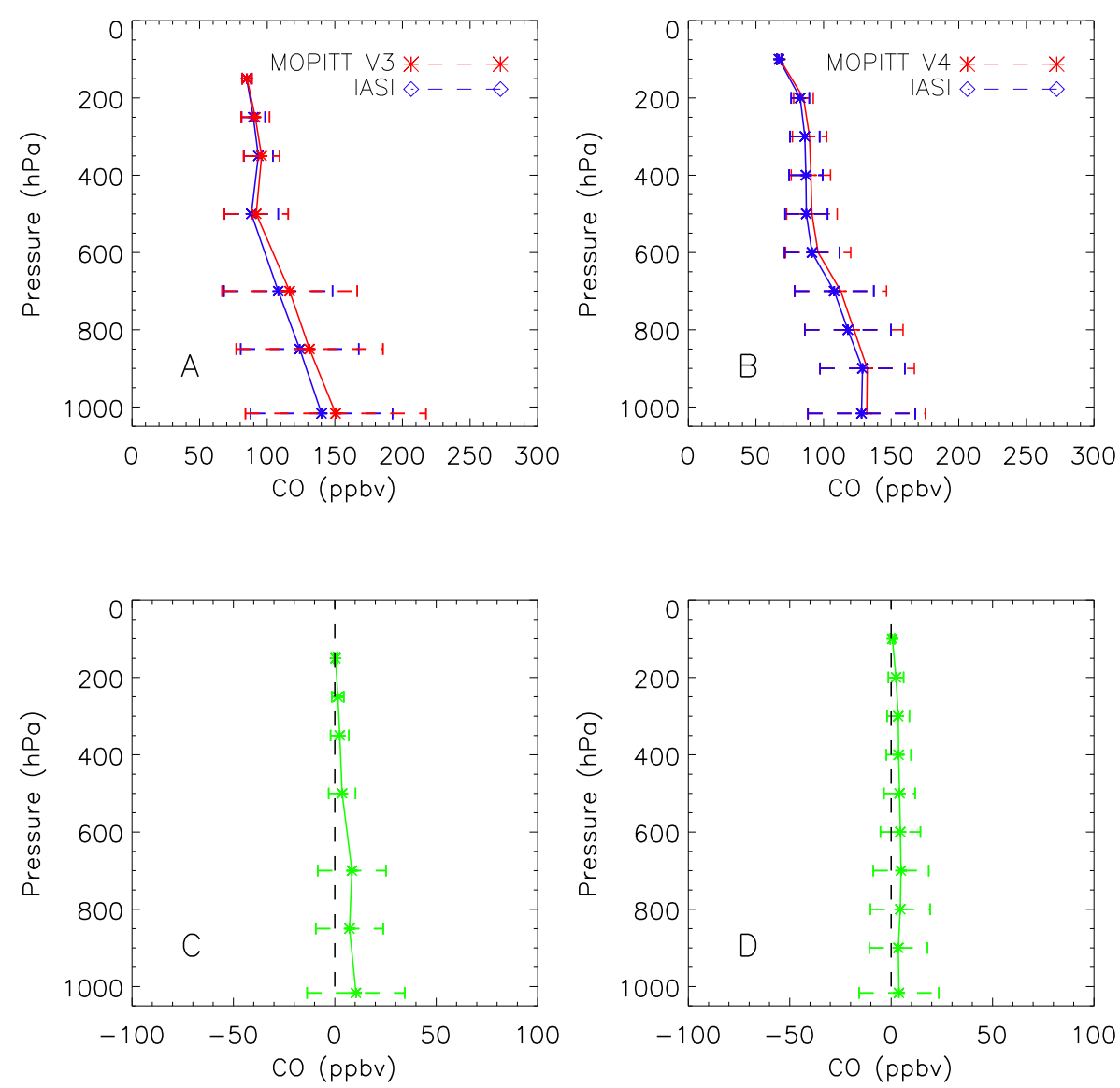

Fig. 13. Same as Fig. 12, but for $\boldsymbol{x}_{\mathrm{MODEL}^{\prime}}^{\mathrm{MOP}^{\prime}}$ and $\boldsymbol{x}_{\mathrm{MODEL}}^{\mathrm{IASI}}$ : (A) adjusted MOPITT V3 and MOPITT-smoothed IASI CO mean profiles; (B) adjusted MOPITT V4 and MOPITT-smoothed IASI CO mean profiles; (C) the mean difference between adjusted MOPITT V3 CO and MOPITT-smoothed IASI CO profiles; and (D) the mean difference between adjusted MOPITT V4 CO and MOPITT-smoothed IASI CO profiles. (A) and (B) are in relation to the retrieval of a true profile, as provided by GEOS-Chem. All comparisons are for over the ocean and during the daytime of 1 September 2007, over the Southern Africa region.

\section{Conclusions}

In this paper, it has been shown that there are a number of important considerations to be taken into account when comparing two satellite data sets with low but differing vertical resolutions. A foundation to the work has been the use of averaging kernels, and it is clear from the studies here that consideration and use of vertical sensitivity functions are necessary for such comparisons to be meaningful. Knowledge of the a priori influence (both in bias and in sensitivity) 
Table 4. $\delta \boldsymbol{x}_{\mathrm{BIAS}}$ for IASI and MOPITT V4 CO retrievals for different scenarios.

\begin{tabular}{|c|c|c|c|c|c|c|c|}
\hline & \multicolumn{2}{|c|}{ day and ocean } & \multicolumn{2}{|c|}{ night and ocean } & & \multicolumn{2}{|c|}{ night and land } \\
\hline & $x^{\mathrm{MOP}^{\prime}}-x^{\mathrm{IASI}^{\prime}}(N=1038)$ & $\delta_{\mathrm{MODEL}^{\prime}}(N=1038)$ & $x^{\mathrm{MOP}^{\prime}}-x^{\mathrm{IASI}^{\prime}}(N=925)$ & $\delta_{\text {MODEL }^{\prime}}(N=925)$ & & $x^{\mathrm{MOP}^{\prime}}-x^{\mathrm{IASI}^{\prime}}(N=211)$ & $\delta_{\text {MODEL }^{\prime}}(N=210)$ \\
\hline \multicolumn{8}{|l|}{$900 \mathrm{hPa}$} \\
\hline Mean (ppv) & $3.1(26.9)$ & $3.5(8.1)$ & $-3.4(30.0)$ & $-2.2(4.4)$ & & $-4.9(48.9)$ & $1.41(5.6)$ \\
\hline Bias (\%) & $2.2(18.7)$ & $2.8(6.3)$ & $-2.7(24.0)$ & $-1.8(3.6)$ & & $-2.7(27.3)$ & $1.0(4.2)$ \\
\hline \multicolumn{8}{|l|}{$500 \mathrm{hPa}$} \\
\hline Mean (ppv) & $2.1(12.0)$ & $4.2(6.3)$ & $3.9(8.0)$ & $0.7(1.9)$ & $3.9(12.4)$ & $0.6(3.7)$ & \\
\hline Bias $(\%)$ & $2.3(12.7)$ & $4.8(7.2)$ & $4.9(10.0)$ & $0.8(2.4)$ & & $3.8(12.0)$ & $0.7(4.4)$ \\
\hline \multicolumn{8}{|l|}{$200 \mathrm{hPa}$} \\
\hline Mean (ppv) & $0.5(5.8)$ & $2.4(3.5)$ & $4.4(11.5)$ & $0.5(1.6)$ & & $5.7(11.0)$ & $0.1(2.6)$ \\
\hline Bias $(\%)$ & $0.5(6.8)$ & $2.9(4.2)$ & $5.5(14.6)$ & $0.6(2.1)$ & & $6.8(13.1)$ & $0.1(3.2)$ \\
\hline \multicolumn{8}{|l|}{ Total column } \\
\hline Absolute Bias (\%) & $2.9(14.7)$ & $2.5(3.2)$ & $4.5(14.4)$ & $0.1(2.1)$ & & $7.4(16.2)$ & $2.1(4.3)$ \\
\hline
\end{tabular}

immediately follows as a requirement and the technique development reported in this paper, following on from the work of Rodgers and Connor (2003), examines how one can perform intercomparisons and deduce valuable information given this information.

The most important steps forward in this paper have been to show how the influence of smoothing error from differing a priori influences may be overcome, in order to deduce some useful information, and how the use of model data as a representation of "truth" can be used to test the comparisons made. A key factor has been to recognise that it is important to perform comparisons for a geographical region where the a priori has been specifically constructed to be appropriate (near optimal) for the same locations as the comparisons; in this case the a priori for IASI retrievals was developed for the same geographic location in which the comparisons are performed. This allows the simpler form of the equations in Rodgers and Connor (2003) to be used. Secondly, application of the same a priori to retrievals from both instruments removes the ambiguities due to differing a priori influences. Thirdly, using the averaging kernels of one instrument to smooth those of the other allows a difference quantity to be computed which is sensitive to difference between the systematic error in the retrievals of one and to the smoothed systematic error of the other i.e. to absolute bias; note this final assessment of error requires that the averaging kernel difference term in Eq. (8) is close to zero as discussed in Sect. 6.1. Finally, the application of the same procedure to model profiles allows the quantities computed to be tested for the mean residual bias arising purely from the retrieval formulations for the two sensors, and for suitability of the techniques.

Using these techniques, the possible causes of the differences between the retrievals of the IASI and MOPITT V3/V4 CO products have been investigated for the defined region of Africa, with consistent a priori information for the IASI retrievals. It was observed that the differences between the standard products were significantly affected by the differing a priori data (both mean profiles, covariance errors, and error correlation lengths) used in the retrievals. To account for this different a priori information in IASI and MOPITT retrievals, IASI a priori profiles and covariance matrices were applied to a modified operational MOPITT retrieval algorithm. The residual differences between the two products were believed to arise from differences in the measurement sensitivity, and this was demonstrated by calculating a smoothing bias, using a set of GEOS-Chem modelled data to represent the truth.

To account for the remaining differences in the retrieved $\mathrm{CO}$ products, the difference functions from Rodgers and Connor (2003) were computed with the constraints noted previously to simplify the equations and results. In effect, MOPITT averaging kernels (from the adjusted MOPITT retrieval scheme) were used to smooth IASI CO retrievals. Differences between the IASI data and the MOPITT V4 data, were shown to be less than $7 \%$ at the MOPITT V4 vertical resolution. For the comparison to MOPITT V3 data, differences were shown to be of the order of $10 \%$, although this result must be treated with caution because of residual smoothing error contributions to the selected difference quantity. This offset is comparable with the results of Deeter et al. (2010). As yet no other work has been published regarding the intercomparison of IASI and MOPITT V4 data products. As well as demonstrating that the ULIRS CO product is in good agreement with an independent satellite data set, the work presented in this paper can also be seen as an initial independent verification of the offset between the MOPITT V3 and V4 products.

The next step in the continuation of this work beyond this techniques paper would be to extend the intercomparison over a larger temporal range, and to different regions. Initially the intercomparison should be widened to incorporate dates from the different seasons, as it would be interesting to see how the IASI and MOPITT CO products compared during a period that was not affected by biomass burning. Such a study would also enable the identification of any inter-annual variability between the two data sets. The intercomparison could then be extended in the spatial domain to include regions other than Africa, especially over land masses which are relatively flat. However, care must be taken when the 
analysis is performed over larger regions because of potential variations in the a priori specifications and larger variations in smoothing error contributions. The emphasis again would be on matching the comparison ensemble with the a priori ensemble and therefore the implications of the approach in this paper would be to perform the comparisons on suitable spatial and temporal timescales with an a priori mean and covariance constructed specifically for the same considerations. Results from different domains (spatial and temporal boxes) could then be aggregated to develop a more global or long-term view; such a study is beyond the scope of this paper. Any such analysis should be performed separately for day and night data, and over the land and ocean.

Whilst one day (1 September 2007) has been selected for this study, over the Tropical African region, the results and their interpretations have shown the importance in understanding the constituent parts of any retrieval scheme, and the effects that any of these underlying inputs may have on the retrieved product. In particular any set of profiles and total column amounts should always be provided with a set of matching a priori and averaging kernels, so that the data can be correctly interpreted, and if needs be compared with another product. The purpose of this paper was develop the techniques needed to assess the consistency between the MOPITT and IASI data, and to investigate the probable causes of differences between these two different products with low vertical resolution. In doing so a greater understanding as to the correct interpretation of both the MOPITT and the ULIRS CO retrieved products has been achieved.

Acknowledgements. IASI has been developed and built under the responsibility of the Centre National d'Etudes Spatiales (CNES, France). It is flown onboard the Metop satellites as part of the EUMETSAT Polar System. The IASI L1 data are received through the EUMETCast near real time data distribution service.

The authors would like to thank the NEODC for access to ECMWF data, the NERC for funding S. M. Illingworth, and EUMETSAT for access to the IASI data. SATSCAN-IR is a project selected by EUMETSAT/ESA under the first EPS/Metop RAO.

Edited by: J.-L. Attie

\section{References}

Barret, B., Turquety, S., Hurtmans, D., Clerbaux, C., Hadji-Lazaro, J., Bey, I., Auvray, M., and Coheur, P.-F.: Global carbon monoxide vertical distributions from spaceborne high-resolution FTIR nadir measurements, Atmos. Chem. Phys., 5, 2901-2914, doi:10.5194/acp-5-2901-2005, 2005.

Bey, I., Jacob, D. J., Yantosca, R. M., Logan, J. A., Field, B. D., Fiore, A. M., Li, Q., Liu, H. Y., Mickley, L. J., and Schultz, M. G.: Global modeling of tropospheric chemistry with assimilated meteorology: Model description and evaluation, J. Geophys. Res.-Atmos., 106, 23073-23095, 2001.
Blumstein, D., Chalon, G., Carlier, T., Buil, C., Hébert, P., Maciaszek, T., Ponce, G., Phulpin, T., Tournier, B., Siméoni, D., Astruc, P., Clauss, A., Kayal, G., and Jegou, R.: IASI instrument: Technical overview and measured performances, in: Society of Photo-Optical Instrumentation Engineers (SPIE) Conference Series, edited by: Strojnik, M., vol. 5543, 2004.

Chipperfield, M. P.: New version of the TOMCAT/SLIMCAT offline chemical transport model: Intercomparison of stratospheric tracer experiments, Q. J. Roy. Meteorol. Soc., 132(617), 11791203, 2006.

Clerbaux, C., Boynard, A., Clarisse, L., George, M., Hadji-Lazaro, J., Herbin, H., Hurtmans, D., Pommier, M., Razavi, A., Turquety, S., Wespes, C., and Coheur, P.-F.: Monitoring of atmospheric composition using the thermal infrared IASI/MetOp sounder, Atmos. Chem. Phys., 9, 6041-6054, doi:10.5194/acp-9-6041-2009, 2009.

Deeter, M., Edwards, D., Gille, J., Emmons, L., Francis, G., Ho.S.P., Mao.D., Masters, D., Worden, H., and Drummond, J.: The MOPITT Version 4 CO Product: Algorithm Enhancements, Validation, and Long-Term Stability, Journal of Geophysical Research D: Atmospheres, 115, 2010.

Deeter, M. N., Emmons, L. K., Francis, G. L., Edwards, D. P., Gille, J. C., Warner, J. X., Khattatov, B., Ziskin, D., Lamarque, J., Ho, S., Yudin, V., Attié, J. L., Packman, D., Chen, J., Mao, D., and Drummond, J. R.: Operational carbon monoxide retrieval algorithm and selected results for the MOPITT instrument, J. Geophys. Res.-Atmos., 108, ACH1-1-ACH1-11, 2003.

Deeter, M. N., Edwards, D. P., and Gille, J. C.: Retrievals of carbon monoxide profiles from MOPITT observations using lognormal a priori statistics, J. Geophys. Res.-Atmos., 112, D11311, doi:10.1029/2006JD007999, 2007a.

Deeter, M. N., Edwards, D. P., Gille, J. C., and Drummond, J. R.: Sensitivity of MOPITT observations to carbon monoxide in the lower troposphere, J. Geophys. Res.-Atmos., 112, D24306, doi:10.1029/2007JD008929, 2007b.

Drummond, J. R. and Mand, G. S.: The measurements of pollution in the troposphere (MOPITT) instrument: Overall performance and calibration requirements, J. Atmos. Ocean. Tech., 13, 314320, 1996.

Dudhia, A.: Michelson Interferometer for Passive Atmospheric Sounding (MIPAS) Reference Forward Model (RFM), Software User's Manual, 2000.

Edwards, D. P.: GENLN2: A general line-by-line atmospheric transmittance and radiance model, NCAR Tech.Note, NCAR/TN-367+STR, 1992.

Edwards, D. P., Halvorson, C. M., and Gille, J. C.: Radiative transfer modeling for the EOS Terra satellite Measurement of Pollution in the Troposphere (MOPITT) instrument, J. Geophys. Res.Atmos., 104, 16755-16775, 1999.

Emmons, L. K., Walters, S., Hess, P. G., Lamarque, J.-F., Pfister, G. G., Fillmore, D., Granier, C., Guenther, A., Kinnison, D., Laepple, T., Orlando, J., Tie, X., Tyndall, G., Wiedinmyer, C., Baughcum, S. L., and Kloster, S.: Description and evaluation of the Model for Ozone and Related chemical Tracers, version 4 (MOZART-4), Geosci. Model Dev., 3, 43-67, doi:10.5194/gmd3-43-2010, 2010.

George, M., Clerbaux, C., Hurtmans, D., Turquety, S., Coheur, P.F., Pommier, M., Hadji-Lazaro, J., Edwards, D. P., Worden, H., Luo, M., Rinsland, C., and McMillan, W.: Carbon monoxide 
distributions from the IASI/METOP mission: evaluation with other space-borne remote sensors, Atmos. Chem. Phys., 9, 83178330, doi:10.5194/acp-9-8317-2009, 2009

Giglio, L., Csiszar, I., and Justice, C. O.: Global distribution and seasonality of active fires as observed with the Terra and Aqua Moderate Resolution Imaging Spectroradiometer (MODIS) sensors, J. Geophys. Res.-Biogeo., 111, G02016, doi:10.1029/2005JG000142, 2006.

Ho, S. ., Edwards, D. P., Gille, J. C., Luo, M., Osterman, G. B., Kulawik, S. S., and Worden, H.: A global comparison of carbon monoxide profiles and column amounts from Tropospheric Emission Spectrometer (TES) and Measurements of Pollution in the Troposphere (MOPITT), J. Geophys. Res.-Atmos., 114, D21307, doi:10.1029/2009JD012242, 2009.

Illingworth, S. M., Remedios, J. J., and Parker, R. J.: Intercomparison of integrated IASI and AATSR calibrated radiances at 11 and $12 \mu \mathrm{m}$, Atmos. Chem. Phys., 9, 6677-6683, doi:10.5194/acp-96677-2009, 2009.

Illingworth, S. M., Remedios, J. J., Boesch, H., Moore, D. P., Sembhi, H., Dudhia, A., and Walker, J. C.: ULIRS, an optimal estimation retrieval scheme for carbon monoxide using IASI spectral radiances: sensitivity analysis, error budget and simulations, Atmos. Meas. Tech., 4, 269-288, doi:10.5194/amt-4-269-2011, 2011.

Kobayashi, H., Shimota, A., Kondo, K., Okumura, E., Kameda, Y., Shimoda, H., and Ogawa, T.: Development and evaluation of the interferometric monitor for greenhouse gases: A highthroughput Fourier-transform infrared radiometer for nadir Earth observation, Appl. Optics, 38, 6801-6807, 1999.

Kopacz, M., Jacob, D. J., Fisher, J. A., Logan, J. A., Zhang, L., Megretskaia, I. A., Yantosca, R. M., Singh, K., Henze, D. K., Burrows, J. P., Buchwitz, M., Khlystova, I., McMillan, W. W., Gille, J. C., Edwards, D. P., Eldering, A., Thouret, V., and Nedelec, P.: Global estimates of $\mathrm{CO}$ sources with high resolution by adjoint inversion of multiple satellite datasets (MOPITT, AIRS, SCIAMACHY, TES), Atmos. Chem. Phys., 10, 855-876, doi:10.5194/acp-10-855-2010, 2010.

Larar, A. M., Smith, W. L., Zhou, D. K., Liu, X., Revercomb, H., Taylor, J. P., Newman, S. M., and Schlüssel, P.: IASI spectral radiance validation inter-comparisons: case study assessment from the JAIVEx field campaign, Atmos. Chem. Phys., 10, 411-430, doi:10.5194/acp-10-411-2010, 2010.

Luo, M., Rinsland, C. P., Rodgers, C. D., Logan, J. A., Worden, H., Kulawik, S., Eldering, A., Goldman, A., Shephard, M. W., Gunson, M., and Lampel, M.: Comparison of carbon monoxide measurements by TES and MOPITT: Influence of a priori data and instrument characteristics on nadir atmospheric species retrievals, J. Geophys. Res.-Atmos., 112, D09303, doi:10.1029/2006JD007663, 2007.
McMillan, W. W., Barnet, C., Strow, L., Chahine, M. T., McCourt, M. L., Warner, J. X., Novelli, P. C., Korontzi, S., Maddy, E. S., and Datta, S.: Daily global maps of carbon monoxide from NASA's Atmospheric Infrared Sounder, Geophys. Res. Lett., 32, $1-4,2005$.

Rinsland, C. P., Luo, M., Logan, J. A., Beer, R., Worden, H., Rider, D., Osterman, G., Gunson, M., Eldering, A., Goldman, A., Shephard, M., Clough, S. A., Rodgers, C., Lampel, M., and Chiou, L.: Nadir measurements of carbon monoxide distributions by the Tropospheric Emission Spectrometer instrument onboard the Aura Spacecraft: Overview of analysis approach and examples of initial results, Geophys. Res. Lett., 33, L22806, doi:10.1029/2006GL027000, 2006.

Rodgers, C.: Inverse Methods for Atmospheric Sounding: Theory and Practice, World Scientific, 2000.

Rodgers, C. D. and Connor, B. J.: Intercomparison of remote sounding instruments, J. Geophys. Res.-Atmos., 108, ACH131-ACH13-14, 2003.

Seemann, S. W., Borbas, E. E., Knuteson, R. O., Stephenson, G. R., and Huang, H.: Development of a global infrared land surface emissivity database for application to clear sky sounding retrievals from multispectral satellite radiance measurements, J. Appl. Meteorol. Clim., 47, 108-123, 2008.

Thompson, A. M.: The oxidizing capacity of the earth's atmosphere: Probable past and future changes, Science, 256, 1157$1165,1992$.

Turquety, S., Hurtmans, D., Hadji-Lazaro, J., Coheur, P.-F., Clerbaux, C., Josset, D., and Tsamalis, C.: Tracking the emission and transport of pollution from wildfires using the IASI CO retrievals: analysis of the summer 2007 Greek fires, Atmos. Chem. Phys., 9, 4897-4913, doi:10.5194/acp-9-4897-2009, 2009.

USGS: US Geological Survey: GTOPO30 Global 30 Arc-second Digital Elevation Model, Tech. rep., http://edcwww.cr.usgs.gov/ landdaac/gtopo30/gtopo30.html (last access: April 2011), 1998.

van der Werf, G. R., Randerson, J. T., Giglio, L., Collatz, G. J., Kasibhatla, P. S., and Arellano Jr., A. F.: Interannual variability in global biomass burning emissions from 1997 to 2004, Atmos. Chem. Phys., 6, 3423-3441, doi:10.5194/acp-6-3423-2006, 2006.

Warner, J., Gille, J., Edwards, D., Ziskin, D., Smith, M. W., Bailey, P. L., and Rokke, L.: Cloud Detection and Clearing for the Earth Observing System Terra Satellite Measurements of Pollution in the Troposphere (MOPITT) Experiment, Appl. Optics, 40, 1269-1284, 2001.

Warner, J., Comer, M. M., Barnet, C. D., McMillan, W. W., Wolf, W., Maddy, E., and Sachse, G.: A comparison of satellite tropospheric carbon monoxide measurements from AIRS and MOPITT during INTEX-A, J. Geophys. Res.-Atmos., 112, D12S17, doi:10.1029/2006JD007925, 2007. 